Revista de Derecho Público: Teoría y Método Marcial Pons Ediciones Jurídicas y Sociales

Vol. 1 | 2020 pp. 7-40 Madrid, 2020

DOI: 10.37417/RPD/vol_1_2020 25

(C) Luciano Parejo Alfonso ISSN: $2695-7191$

Recibido: 19/11/2019 | Aceptado: 16/12/2019

Editado bajo licencia Creative Commons Attribution 4.0 International License.

\title{
LA ACTUACIÓN ADMINISTRATIVA A CABALLO DE LA DIVISIÓN ENTRE NORMACIÓN Y SIMPLE EJECUCIÓN Y EL CASO DE LA PLANIFICACIÓN Y EL PLAN ${ }^{1}$
}

\author{
ADMINISTRATIVE ACTION ASTRIDE THE DIVISION BETWEEN \\ NORMATION AND SIMPLE EXECUTION AND THE CASE OF PLANNING \\ AND PLAN
}

\author{
Luciano Parejo Alfonso \\ Catedrático Emérito de Derecho Administrativo \\ Universidad Carlos III de Madrid
}

RESUMEN: Partiendo del análisis de la producción normativa y la aplicación como una de las dicotomías que estructuran nuestro Derecho y tras comprobar su persistencia inercial a pesar de las profundas transformaciones experimentadas por el Estado y su Derecho, el trabajo postula la diferenciación entre aplicación y ejecución (administrativa) teniendo a la vista el desarrollo de formas de actuación del poder público administrativo de difícil encuadre en la clasificación bipartita norma-acto, y sostiene la procedencia del reflejo de la singularidad de aquellas formas en el régimen común de invalidez de la actuación administrativa con apoyo en el caso testigo de la planificación.

PALABRAS CLAVE: normación; aplicación; ejecución; planificación; plan; naturaleza de las decisiones y régimen de su invalidez.

ABSTRACT: Starting from the premise that the analysis of the normative production and its application is one of the dichotomies that structure our legal system, and once its natural continuity

${ }^{1}$ En el texto se emplean las siguientes abreviaturas: BVerfGE: Bundesverfassungsgerichtsentscheidung; CE: Constitución española de 1978; DÖV: Die Öffentliche Verwaltung; DVBl: Deutsches Verwaltungsblatt; LJCA: Ley 29/1998, de 13 de julio, reguladora de la jurisdicción contencioso-administrativa; LPAC: Ley 39/2015, de 1 de octubre, del procedimiento administrativo común de las Administraciones públicas; LRJSP: Ley 40/2015, de 1 de octubre, de régimen jurídico del sector público; RAP: Revista de Administración Pública; RDUM: Revista de Derecho Urbanistico y Medio Ambiente; VVDStRL: Veröffentlichungen der Vereinigung der Deutschen Staatsrechtslehrer. 
has been proved despite the profound transformations suffered by the State and the Law, this paper postulates the difference between the application of the Law and its administrative execution taking into account the development of the ways in which the public power acts that are very difficult to frame within the simple norm-act differentiation. The paper states the relevance of the reflection on the singularity of that behavior of the public power in the common legal regime of the invalidity of the administrative action, with support in the witness case of the planning.

KEYWORDS: normation; application of the Law; administrative execution; planning; plan; nature of decisions and their invalidity regime.

SUMARIO: 1. LA DICOTOMÍA PRODUCCIÓN DE REGLAS O NORMAS Y APLICACIÓN O EJECUCIÓN DE LAS MISMAS - 2. LA APLICACIÓN DEL DERECHO Y LA EJECUCIÓN ADMINISTRATIVA - 3. EL PROGRESIVO DESBORDAMIENTO POR LA FUNCIÓN EJECUTIVA DE LA ADMINISTRACIÓN PÚBLICA DE LOS LÍMITES DERIVADOS DE LA DICOTOMÍA ESTABLECIDA — 4. LA PLANIFICACIÓN Y EL PLAN COMO CASO TESTIGO: 4.1. Una singular forma de actuación con un papel cada vez más central. 4.2. Una primera aproximación al fenómeno. 4.3. Características distintivas de la planificación y el plan. 4.4. El plan como forma específica de actuación. 4.5. La cuestión, irresuelta, de la naturaleza del plan y el régimen jurídico de su invalidez. - 5. APÉNDICE - 6. BIBLIOGRAFÍA.

\section{LA DICOTOMÍA PRODUCCIÓN DE REGLAS O NORMAS Y APLICACIÓN O EJECUCIÓN DE LAS MISMAS}

Como ha recordado recientemente J. ISENSEE, las fronteras o límites son estructuras generales, omnipresentes, del orden jurídico ${ }^{2}$. Es claro que estas estructuras guardan íntima relación con las diferenciaciones dicotómicas (p. ej. y en lo que aquí interesa: Derecho público-Derecho privado; normación-ejecución) con las que viene funcionando el Derecho, desde luego el continental europeo. La construcción

2 Josef ISENSEE (Grenzen. Zur Territorialität des Staates, Duncker \& Humblot, Berlin, 2018, pp. 28 y 209) argumenta, en efecto, a este respecto que:

a) Límites existen no solo en el espacio geofísico, sino también en esferas no territoriales del Derecho pensadas por analogía al espacio: ámbitos de protección y competencias, instituciones, supuestos y derechos subjetivos. Constituyen, por ello, una forma general de realización del Derecho, en la que el límite se ofrece como una línea ideal que (en los términos que resulten del régimen de la correspondiente materia) tanto puede dividir nítidamente, como permitir transiciones blandas.

b) Los límites son, además de sustantivos, temporales: la vigencia de una norma y la posibilidad de ejercicio de una facultad se determinan por términos, plazos, fecha determinada. El decurso del tiempo vital tiene fechas fijas: el comienzo de la capacidad jurídica, la capacidad de obrar, el Derecho electoral, pero también el tiempo de trabajo o servicio, la edad de jubilación, los límites de edad.

c) Límites hay en todas relaciones jurídicas: en las de coordinación (entre Estados o sujetos ordinarios) y en las de subordinación (entre la comunidad internacional y los Estados; entre estos últimos y los ciudadanos).

d) Los límites diferencian el orden regular de competencias y procedimientos de los supuestos de necesidad y, con estos, la normalidad y la excepción. Y se manifiestan en el solapamiento de las formas del Derecho público y el privado, el contenido de las normas prescriptivas y descriptivas, el tipo de validez del Derecho estricto y dispositivo. 
de este, a su vez, sobre tales diferenciaciones (y los límites que estas presuponen) es tributaria de la del Estado clásico o liberal de Derecho, cuya evolución — habiendo ido de consuno, durante mucho tiempo, con la del Estado - ha determinado la identidad de uno y otro ${ }^{3}$ sobre la base de la soberanía del segundo y la compleciónunidad del primero en tanto que sistema autoproducido de normas ${ }^{4} \mathrm{y}$, por tanto, autopoiético $^{5}$.

Sin perjuicio de que ni el concepto "normación” (creación del Derecho objetivo; producción de normas ${ }^{6}$ ), ni el de "fuentes del Derecho" (aún limitado a sus dimensiones de origen y manifestación de las normas o reglas) sean precisos ${ }^{7}$, aquí puede partirse de su identificación con producción estatal de normas jurídicas ${ }^{8} y$, por tanto, de su determinación en el Derecho positivo, es decir, en el Código Civil y la Constitución ${ }^{9}$.

Para el Código Civil las fuentes del Derecho son (art. 1.1) solo la Ley, la costumbre y los principios generales del Derecho (categorías todas ellas de perfiles no precisamente nítidos) y la Ley parece ser igual a disposición (art. 1.2), conteniendo una y otra "normas jurídicas" (arts. 1.5, 3.1 y 4.1) ${ }^{10}$. La Constitución no desautoriza

3 Josef ISENSEE, op. cit. en nota anterior, p. 73. Paul KIRCHHOF ["Rechtsquellen und Grundgesetz", en Christian STARCK et al. (eds.), Bundesverfassungsgericht und Grundgesetz. Festgabe aus Anlass des 25jährigen Bestehens des Bundesverfassungsgerichts, J. C. B. Mohr (Paul Siebeck), Tübingen 1976, p. 52] sostiene, por su parte, que el Derecho se forma en el Estado y no solo por el Estado.

${ }^{4}$ Hans KELSEN, Teoría pura del Derecho, Trotta, Madrid, 2011 (la primera edición de esta obra data de 1934).

5 Niklas LUHMANN, Das Recht der Gesellschaft, Suhrkamp, Frankfurt 1993, p. 39 (existe traducción al español de la editorial Herder, México, 2015).

${ }^{6}$ La noción de "norma" dista igualmente de tener significado preciso en el lenguaje jurídico, pues este no suele responder a los conceptos bien establecidos en la teoría general del Derecho. De ahí que aquí se sigue más bien un concepto pragmático de norma jurídica (en el sentido acuñado por Juan Alfonso SANTAMARÍA PASTOR, Principios de Derecho Administrativo General, t. I, Iustel, 5.a ed., 2016, p. 96: la proposición prescriptiva de carácter jurídico empleada por los diferentes operadores jurídicos como parte del razonamiento tendente a dar solución correcta a los conflictos que se plantean).

7 La expresión "fuentes del Derecho" es, en efecto, equívoca y multívoca, por lo que no es sorprendente que haya dado lugar a sucesivas concepciones teóricas que difícilmente podrán llegar a ser nunca definitivas. Véase a este respecto Antonio Enrique PÉREZ LUÑO, El desbordamiento de las fuentes del Derecho, Wolters Kluwer, Madrid 2011 (pp.17 y 18), autor que, en el capítulo I de su obra, hace un repaso de las posiciones fundamentales al respecto de Georges GURVITCH, Alf ROSS, Hans KELSEN, Herbert L. HART y Ronald DWORKIN. Así como las más recientes de Niklas LUHMANN, Gunther TEUBNER, Robert ALEXY y Guido FASSÒ, sin dejar de hacer referencia a las mantenidas en el movimiento anglosajón llamado Critical Legal Studies.

Para Paul KIRCHHOF (op. cit. en nota 2, p. 53) el concepto "fuente del Derecho" dibuja una impresionante imagen lingüística de la formación del Derecho. Describe una substancia preexistente, de cuya existencia se sabe, pero cuyos contornos concretos permanecen ocultos. Designa además la emergencia continua de esa fuente constituida o dejada en su estado natural.

${ }^{8}$ La denominación del título preliminar del Código civil emplea la expresión "normas jurídicas".

9 Paul KIRCHHOF (op. cit. en nota 2, pág. 59) sostiene que, según la Constitución, el orden jurídico se apoya sobre el Derecho positivo establecido por los órganos estatales.

10 Aunque el art. 1.5 se refiere solo a los tratados internacionales, la alusión genérica a las "normas" que hacen los arts. 3.1 y 4.1 permite extrapolar aquella referencia sin dificultad a la Ley-disposición. 
este esquema, pero lo precisa, enriquece y complementa y, por tanto, complica significativamente en los siguientes términos:

a) Aunque del propio esquema establecido por el Código Civil se deduzca obviamente que las fuentes del Derecho (y, por tanto, del Derecho objetivo) no son cuestión solo teorética, sino también y primariamente objeto de decisión del poder estatal, la norma fundamental así lo declara expresamente. Además de dar por supuesto (arts. 1 y 2) que ella misma resulta de la decisión constituyente del pueblo soberano, reserva al Estado central ya constituido, en efecto (art. 149.1.8 ${ }^{\mathrm{a}}$ ), el establecimiento de las normas para "resolver los conflictos de Leyes y determinación de las fuentes del Derecho".

b) Emplea el concepto "Ley" normalmente en sentido formal ${ }^{11}$ (en el que el principio democrático y, por tanto, la adopción por el órgano parlamentario representativo siguiendo el procedimiento establecido a tal efecto, son decisivos ${ }^{12}$ ) pero también, a veces, en sentido aparente o claramente material ${ }^{13}$. Y equipara la Ley a documento en el que se plasma la norma: el texto legal (como resultado de la refundición de varios en uno solo: art. 82). De lo que resulta que la Ley enuncia o contiene normas.

c) Erige el nomen "disposición”, equivalente a "norma”, en categoría comprensiva de las dos siguientes especies: 1) disposición con rango o fuerza de Ley (la Ley formal en sus distintas variantes) ${ }^{14}$, disposición legislativa provisional —el Decreto-Ley ${ }^{15}$-, disposición legislativa expresada en textos articulados y refundidos, cuyo "ámbito normativo" está predeterminado por Ley formal de delegación ${ }^{16}$; y 2) disposición administrativa o Reglamento ${ }^{17} /{ }^{18}$.

11 Así cuando se refiere a la reserva absoluta o relativa para la regulación de los derechos y deberes constitucionales y los principios rectores de la política social y económica (art. 53), la "Ley orgánica” o la "Ley de bases" o de delegación.

12 En este sentido es claro el tercer párrafo del preámbulo del texto fundamental cuando dice: "Consolidar un Estado de Derecho que asegure el imperio de la ley como expresión de la voluntad popular".

13 Así, cuando emplea la equívoca expresión "la Constitución y la Ley” (aunque el alcance de la misma es desde luego interpretable según el contexto en que se utiliza y, por tanto, dudoso). Pero también cuando precisa, en el art. 10.1 CE, "el respeto a la Ley y a los derechos de los demás" como límite al libre desarrollo de la personalidad.

14 Arts. 153, a), 161.1, a), 163 y 164 CE.

15 Art. 86.1 CE.

16 Art. 82.5 CE.

17 Arts. 97, 105, a) y 106.1 CE.

18 La especie "Reglamento" no es desconocida para el Código Civil. Así, su art. 350 sujeta las obras, plantaciones y excavaciones que puede hacer el propietario de un terreno a las Leyes (sobre minas y aguas) y los "Reglamentos de policía"; sus arts. 550 y 551 establecen que las servidumbres establecidas para utilidad pública o comunal y las impuestas por la Ley en beneficio de los particulares se rigen, respectivamente, por "las leyes y reglamentos especiales que las determinen" y "las disposiciones [del título del que forma parte el precepto], sin perjuicio de lo que dispongan las leyes, reglamentos y ordenanzas generales o locales sobre policía urbana o rural"; su art. 558 obliga a indemnizar el paso por predio ajeno de aguas "en la forma que se determine por las leyes y reglamentos"; su art. 570 determina que las servidumbres de paso para ganados se rigen por "las ordenanzas y reglamentos del ramo"; sus arts. 589 y 
d) Aclara, en todo caso, que las disposiciones normativas fruto de decisiones de los órganos estatales correspondientes no agotan el Derecho objetivo identificado como "ordenamiento jurídico" ${ }^{19}$. De donde se sigue que este último es el conjunto total de las normas jurídicas ${ }^{20}$ que rigen en el Estado constituido por la norma fundamental; conjunto que puede conceptuarse igualmente - como hace J. A. SANTAMARÍA PASTOR ${ }^{21}$ - como sistema (complejo, en tanto que alberga en su seno subsistemas) y del que el Tribunal Constitucional ${ }^{22}$ predica las notas de "unidad", "juridicidad" (que lo distingue de otros órdenes prescriptivos) y "efectividad global".

En tanto que al ordenamiento, es decir, a las normas jurídicas es inherente, pues, la pretensión de efectividad o, lo que es lo mismo, de hacerse realidad, precisan ser seguidas de un conjunto de actividades dirigidas derechamente a ajustar aquella realidad a sus proposiciones ${ }^{23}$ : la aplicación lato sensu. Ésta resulta ser, así, un resultado,

590, relativos a la edificación o construcción cerca de plazas fuertes o de pared ajena o medianera, sujeta las obras bien a "las leyes, ordenanzas y reglamentos particulares de la materia", bien a "los reglamentos y usos del lugar"; su art. 1109, referente al devengo de intereses, determina que los Montes de Piedad y Cajas de Ahorro se rigen por "sus reglamentos especiales"; su art. 1585 prescribe la observancia en el servicio de los trabajadores asalariados de "las leyes y reglamentos especiales"; su art. 1603 salva la aplicación en todo caso, en los transportes, de "lo que prevengan las leyes y los reglamentos especiales"; y sus arts. 1757 y 1873 sujetan los establecimientos de préstamos sobre prendas, a "los reglamentos que les conciernan".

19 Arts. 1.1 (según el que los que denomina "valores superiores" forman también parte del ordenamiento jurídico); 8.1 (que habla de defensa del "ordenamiento constitucional"), 9.1 y 2 (a cuyo tenor los poderes públicos están sujetos, además de a la Constitución, "al resto del ordenamiento jurídico", garantizando la norma fundamental determinados "principios"), 57.3 (que alude al "Derecho" como instancia capaz de llamar las líneas de sucesión a la Corona), 86.1 (que vuelve a referirse al "ordenamiento", así como al "Derecho electoral"), 96.1 (que se refiere al "ordenamiento interno" y a "las normas generales del Derecho internacional"), 103.1 (que somete a la Administración pública a "la Ley y el Derecho"), 147 (que dispone el respeto y amparo por el Estado de los Estatutos de Autonomía como "parte integrante de su ordenamiento jurídico"), 149.1.8 (que, al tratar de la "legislación civil" menciona los "Derechos civiles, forales o especiales") 149.3 (que se refiere al "Derecho estatal" y al "Derecho de las Comunidades Autónomas"), 157.1, d) (que incluye entre los recursos de las Comunidades Autónomas los ingresos de "Derecho privado") y disp. ad. 2. (que se refiere a los Derechos forales en el ámbito del Derecho privado").

20 Para la más reciente jurisprudencia del Tribunal Supremo (SSTS 1278/2019, de 30 de septiembre, y 2813/2019, de 16 de septiembre, entre otras), la disposición de carácter general se caracteriza justamente por su "contenido normativo" (esto es: el establecimiento de normas) o "vocación regulatoria" (esto es: la de establecer reglas). Quiere decir que se adhiere a un criterio "ordinamental" para identificar lo normativo.

${ }^{21}$ Juan Alfonso SANTAMARÍA PASTOR, op. cit. en nota 5, p. 110. Ese autor ha prestado atención a la evolución de las fuentes. Véase su trabajo "El sistema de fuentes del Derecho en los primeros 50 ańos de vida de la Revista de Administración Pública (1950-2000)”, RAP, núm. 150, 1999, pp. 533-576.

${ }^{22}$ SSTC 58/1985, de 30 de abril, y 76/1986, de 9 de junio.

23 En este sentido Luis DÍEZ-PICAZO y Antonio GULLÓN, Sistema de Derecho civil, 8.a ed., Tecnos, Madrid, 2015, p. 164.

Antes, Federico DE CASTRO Y BRAVO, Derecho civil de España, Parte General I, IEP, Madrid, 1955, pp. 487 y 488, recordando que E. HUBER había dicho a principios del siglo XX que el Derecho está para que se realice, destaca que el Derecho, para llegar a serlo, ha de hacerse real. Por ello, la creación 
lo que vale decir, un consecuente de la norma jurídica (que es, por tanto, un antecedente necesario de ella ${ }^{24}$. De donde deriva la diferenciación y aún la contraposición entre la una y la otra: la aplicación presupone la norma previa, de modo que en ella no puede haber ya propiamente nueva producción normativa y sí solo actualización (en la realidad) de la previa pertinente al caso ${ }^{25}$. Pero también, lo que no es menos importante, la subordinación de la aplicación a la norma a que se refiera.

\section{LA APLICACIÓN DEL DERECHO Y LA EJECUCIÓN ADMINISTRATIVA}

La sistemática interna del título preliminar del Código Civil contrapone, en efecto, ambas categorías (las fuentes del Derecho - Cap. I- a la aplicación de las normas - Cap. II- $)^{26}$, dedicando a esta última, sin embargo, una regulación más bien pobre por limitada a la interpretación y la aplicación analógica o equitativa de las normas. La Constitución recoge esta contraposición tanto al reservar en todo caso al Estado stricto sensu (art. 149.1.8 ${ }^{\text {a }}$ la competencia para, de un lado, determinar las fuentes del Derecho, y, de otro lado, establecer "las reglas relativas a la aplicación y la eficacia de las normas jurídicas", como al definir la esfera de tareas del complejo Gobierno-Administración (art. 97), al que, en efecto, atribuye la "función ejecutiva" y le asigna, separada y singularmente, la potestad reglamentaria, es decir, la del dictado de disposiciones de carácter general de tal rango (el cual no se inscribe, por tanto, en la referida función). Pero al mismo tiempo vuelve más compleja la fase consecuente analizada, pues mientras califica esta, desde la perspectiva de la legislación civil (art. 149.1.8 a), de "aplicación", se refiere a ella, desde la óptica del cometido constitucional propio del complejo Gobierno-Administración, como "ejecución” (arts. 97 y 152.1). Lo que parece querer decir que:

- La aplicación stricto sensu se refiere primariamente a normas cuya efectividad solo requiere del acto o actos jurídicos que, siendo suficientes al efecto, las hagan realidad en el caso concreto y en el plano de las relaciones jurídicas de coordinación

de normas no está completo hasta que consiga su fin. Define kelsenianamente, por ello, la aplicación como tránsito desde la regla general a la decisión particular.

${ }^{24}$ Esta diferenciación luce claramente en la neta diferenciación por la Constitución, al determinar el contenido de la función judicial (art. 117.3) entre juzgar (decidir el Derecho; antecedente, título habilitante) y ejecutar lo juzgado (llevar a efecto lo decidido; consecuente).

${ }_{25}$ Según Paul KIRCHHOF (op. cit. en nota 2, pp. 55 y 80), la proposición jurídica (entendida como toda regla determinante del comportamiento que puede ser aplicada repetidamente a casos similares) contiene Derecho en reposo que solo se hace eficaz en el acto jurídico. Y las regulaciones en forma de proposición jurídica entregan al acto jurídico la determinación del Derecho en la cuestión concreta.

26 Luis DÍEZ-PICAZO y Antonio GULLÓN (op. cit. en nota 22, p. 164) señalan: “En este sentido la aplicación de las normas puede establecerse - parece que el legislador lo ha establecido- en tres niveles: $1^{\circ}$. Mediante la contraposición entre producción del Derecho (fuentes) y aplicación del mismo; $2^{\circ}$. Mediante la contraposición entre un Derecho teorizado o abstracto y un Derecho colocado sobre la realidad cotidiana o practicado". 
entre sujetos no dotados de autotutela y está entregada, por ello, a dichos sujetos y, en último término, al Juez.

- La ejecución se predica, sin embargo, de normas que - aun precisando aplicación- la desbordan, por cuanto su efectividad o realización depende de la acción, en su caso continuada y no solo jurídica, de otro poder público (cabalmente denominado por ello ejecutivo), es decir, que van más allá en tanto que programan tal acción ulterior de ese otro poder público. Lo que no quiere decir que la ejecución (administrativa) no responda también al modelo estrictamente aplicativo, pues el acto administrativo - tal como esta categoría ha acabado decantándose a partir de su origen francés y a través de su traducción alemana por O. MAYER ${ }^{27}$ - se caracteriza por su referencia a un caso individual o concreto en el que agota sus efectos. En la CE esta característica luce en la diferenciación del procedimiento de elaboración de disposiciones administrativas (en el que es preciso el trámite de audiencia de los ciudadanos en plural en la medida en que "les afecten" tales disposiciones) y aquel a través del cual deben dictarse los actos administrativos (en el que solo ha de garantizarse la audiencia, cuando proceda, del interesado, en singular) [art. 105, a) y c)]. En sentido estricto, el acto es, pues y en tanto que jurídico, formal y resolutorio de un procedimiento, aplicación stricto sensu de la correspondiente norma previa, reflejando la dicotomía tradicional. A lo más que puede llegar un acto, pues, es a tener destinatario plúrimo, pero nunca a alcanzar la condición de norma integrante del ordenamiento jurídico.

Sin perjuicio, pues, de que "ejecución" tenga una significación que, por amplia, incluye la "aplicación", lo cierto es que uno y otro término, ya incluso en el lenguaje ordinario, presentan significado no idéntico: mientras la aplicación es la acción y el efecto de aplicar, la ejecución alude a poner por obra algo ${ }^{28}$. De la CE resulta con naturalidad que la ejecución administrativa consiste en una actuación, de acuerdo con determinados principios (entre ellos el de eficacia, es decir, el de realización efectiva del interés general), de muy amplio espectro (como resulta de su visión desde la óptica de la responsabilidad patrimonial: servicios públicos; art. 106.2 CE). Así es porque el texto constitucional: i) impone a los poderes públicos (art. 9.2 CE) la promoción de las condiciones para que la libertad y la igualdad de individuos y grupos sean reales y efectivas y la remoción de los obstáculos que impidan o dificulten su plenitud; ii) otorga a la función ejecutiva asignada al Gobierno-Administración un carácter necesariamente residual, pues ha de comprender todo lo que no es ni legislar, ni juzgar y ejecutar lo juzgado; e iii) incluye en lo ejecutivo de lo directivo gubernativo (propio del Gobierno: la dirección de la política interior y ejercicio de la función ejecutiva; art. 97.1 CE) y lo administrativo, es decir, el servicio al interés general (propio de la Administración; art. 103.1 CE). Pues la actuación en que se traduce la

27 Véase Gustave PEISER, Droit administratif, 10. a ed., Mementos Dalloz, Paris, 1981, p. 18; y Hans-Uwe ERICHSEN, "Das Verwaltungshandeln”, en Hans-Uwe ERICHSEN y Wolfgang MARTENS (eds.), Allgemeines Verwaltungsrecht, 9. ${ }^{a}$ ed., Walter de Gruyter, 1992, pp. 227 y 228.

${ }_{28}$ Según las acepciones aquí más pertinentes del Diccionario de la Real Academia de la Lengua. 
ejecución administrativa ha de consistir, precisamente por ejecutiva, en todo lo necesario para realizar el interés general y no solo, por tanto, en la verificación de operaciones jurídicas. Lo que significa: la actuación administrativa no se limita a aplicar la Ley y el Derecho, sino que la rebasa, aunque deba desplegarse con "sometimiento pleno" a una y otro, por lo que los Tribunales controlan precisamente su legalidad y el "sometimiento de esta [la actuación] a los fines que la justifican" (art. 106.1 CE). Por ello se ha podido decir que, aunque las normas dirigen la actuación administrativa, precisan de su transformación en supuestos reales justamente mediante dicha actuación, de suerte que el contenido normativo directivo de la ejecución solo se alumbra plenamente en la praxis ejecutiva. En el contexto del principio de legalidad no es posible, así, la comprensión unidireccional de la relación entre norma jurídica abstracta-general y ejecución que la concreta ${ }^{29}$.

\section{EL PROGRESIVO DESBORDAMIENTO POR LA FUNCIÓN EJECUTIVA DE LA ADMINISTRACIÓN PÚBLICA DE LOS LÍMITES DERIVADOS DE LA DICOTOMÍA ESTABLECIDA}

La diferenciación entre producción normativa y realización de las normas ya existentes es en todo caso relativa (depende de la perspectiva), como resulta ya, claramente, de la teoría positivista de la construcción gradual del Derecho elaborada por $\mathrm{H}$. KELSEN con la contribución, no precisamente accesoria, de A. MERKL ${ }^{30}$. Diferenciación, relativa, esta que lleva de la mano a la que separa Derecho privado (campo propio de la aplicación y su resultado último: la Sentencia judicial o la resolución arbitral) y Derecho público y, más precisamente, administrativo (campo propio de la ejecución y su resultado, que puede circunscribirse a un acto o resolución ${ }^{31} \mathrm{o}$ extenderse a una actividad o actuación ${ }^{32}$ por más que susceptible de control judicial último). Pues el Derecho privado establece las reglas del juego recíproco de las actuaciones de los sujetos ordinarios que estos definen con autonomía y capacidad jurídica general (es decir, concretando sus fines e intereses sobre la base del valor de la libertad concretada en una pluralidad de derechos fundamentales), es decir, no predetermina los fines y objetivos que dichos sujetos pueden perseguir, individual o asociadamente, sino que, todo lo más, excluye o prohíbe los considerados ilícitos; lo que quiere decir: no le incumbe la realización efectiva de los expresados fines e intereses. Lo propio del Derecho público (concretamente: administrativo) es, sin embargo, la precisión de los fines y objetivos colectivos fuera del alcance de los sujetos ordinarios (el interés general) en el proceso continuado de desarrollo del orden constitucional y cuya realiza-

29 Véase Oliver LEPSIUS, “Themen einer Rechtswissenschaftstheorie”, en Oliver LEPSIUS y Matthias JESTAEDT (eds.), Rechtswissenschaftstheorie, Mohr Siebeck, Tübingen, 2008, pp. 1, 35 y 43.

30 Véase Patricia CUENCA GÓMEZ, "Aspectos clave de la teoría del Derecho de Adolf J. Merkl”, Revista Telemática de Filosofía del Derecho, núm. 17, 2014, pp. 167-202.

31 Es decir, una resolución (acto decisorio típico; art. 88 LPAC) o acto de trámite cualificado equivalente a una decisión del asunto; así como, en último término, una Sentencia judicial.

32 A ellas se refieren las rúbricas del título II y de su Capítulo I LPAC y el art. 1 LJCA. 
ción este postula imperativamente, es decir, le incumbe, por lo que aquella precisión debe ser seguida necesariamente de una actuación programada y controlada al efecto.

El reconocimiento de la relatividad de la diferenciación de normación y ejecución (aplicación) no es de ahora. Así, por ejemplo, P. KIRCHHOF ${ }^{33}$, sin plantearse siquiera las transformaciones experimentadas por el Estado y el Derecho (a las que inmediatamente se hará alusión y que, en lo esencial, aún estaban por venir cuando dicho autor escribe a principios de la segunda mitad de los ańos setenta del siglo XX), señala que cada proposición jurídica contiene también el encargo de hallar el objeto y el contenido de una regla del presente y acorde con la situación. Según él, la proposición jurídica sale del anonimato del lenguaje cuando desencadena un acto jurídico producido objetivamente, pero conforme a la peculiaridad del caso concreto. De suerte que si el encargado de la producción de un acto jurídico comprueba, al formar dicho acto, que en el asunto se plantean al Derecho cuestiones en todo similares, el acto jurídico producido para un determinado caso puede fungir como ejemplo para otros ulteriores, seńalando a partir de entonces la similitud, relevante jurídicamente, de posteriores casos, y operar así como una proposición jurídica. Esta operación implica el efecto de formación por un acto de una regla, que encuentra su expresión más clara en la Sentencia judicial resolutoria de un "caso modelo" y se compendia — como "decisión de principio" - en forma de una proposición jurídica; lo cual es posible porque el Derecho no se agota en la Ley, permitiendo así que la decisión judicial cumpla, en sustitución del legislador, tareas normativas ${ }^{34}$. Pero sostiene igualmente que, así como pretendidos actos administrativos concretos tienen efectos de amplio espectro ${ }^{35}$ y algunas decisiones consideradas como disposiciones (como un plan de urbanismo) pueden ser descompuestas en una suma de actos concretos, así también en tal tipo de actos o decisiones el círculo de destinatarios se pierde en "la generalidad" cuando la Administración adopta medidas globalmente directivas.

Pero la enorme inercia de la diferenciación dicotómica se muestra en su resistencia frente a las transformaciones radicales que ya ha experimentado y a las que continúa sujeto el Estado-Derecho ${ }^{36}$ según la imagen acuñada en el Estado liberal de Derecho clásico, el cual enfatizaba - sobre el presupuesto de la distancia entre Estado y

33 Paul KIRCHHOF, op. cit. en nota 2, pp. 98, 99 y 104.

34 Estas consideraciones llevan de la mano a la previsión en nuestro orden contencioso-administrativo de los supuestos de extensión a otros asuntos (concurriendo, entre otros requisitos, la existencia de identidad de la situación jurídica o "idéntico objeto") de los efectos de una Sentencia ya recaída y firme en un asunto tributario, de personal al servicio de la Administración y de unidad de mercado, (arts. 110 y 111, este último en relación con el 37.2, LJCA).

35 En nuestro ordenamiento puede pensarse, por ejemplo, en las homologaciones de vehículos o aparatos y, más claramente aún, las señales de tráfico, cuyo mandato no se consume en cada caso de observancia o infracción, de modo que se acerca mucho, no ya a un acto plúrimo, sino a una regla, norma o disposición administrativa.

36 Véanse al respecto las interesantes consideraciones de Karl-Heinz LADEUR, Was bedeutet die "Normativität des Rechts in der postmodernen Gesellschaft? - Vorüberlegungen zur Beobachtung des Rechtssystems durch die Rechts- und die Politikwissenschaft_, accesible en http://www2.jura.uni-hamburg. de/ceri/publ/A2.12.09-neu.pdf. 
ciudadano - la abstracción de la Ley en tanto que enunciado de una norma general con vigencia tendencialmente indefinida y situada en la cúspide del ordenamiento. La razón radica, en última instancia, en que el Derecho, por su pretensión de influir en la realidad social, se ha manejado y maneja esencialmente en y para la práctica, de suerte que - a pesar de la contraposición teórica de los sistemas continental y del common law - lo que sea Derecho depende en realidad del "caso jurídico" dominado por análisis, comentarios y convenciones dogmáticos y de la praxis judicial. Pero el caso es constituido siempre por el Derecho, por ser falso, en realidad, el modelo ideal de sucesión caso fáctico-subsunción en una regla general preexistente del que se ha nutrido el positivismo del Derecho. Pues para este la única cuestión jurídica relevante es la de la inserción de toda nueva decisión en el tejido jurídico existente, en modo alguno la eficacia, racionalidad, eficiencia y justicia de aquella. En contra de tal modelo, sin embargo, creación y aplicación aparecen imbricados circularmente en el Derecho ${ }^{37}$ : cada aplicación es al mismo tiempo modificación gracias a que en la aplicación se neutraliza/obvia el principio de que procura solo conocimiento (excluyendo la creación); neutralización, que es irrelevante para el sistema mientras pueda ocultarse (como efectivamente se hace) la apuntada imbricación mediante la construcción formal deductiva o derivativa del discurso jurídico que salva el paradigma de la vigencia, que presupone siempre la existencia previa (a la aplicación) de una norma.

Obviamente, las apuntadas transformaciones no han podido dejar de tener notables repercusiones en las formas de producción y aplicación-ejecución del y "en" el Derecho. Desde su inicial configuración como interventor (que presuponía la capacidad social de generación espontánea de orden) y tras una fase prestacional, el Estado liberal ha adquirido, en efecto, la condición de preventivo y regulador-garante de la dación de bienes y prestación de servicios abierto a la integración supranacional y la comunidad internacional, que incorpora la ponderación caso a caso, coloca la Ley en una posición secundaria y el principio de proporcionalidad en una de primer plano (a fin de poder delimitar y compatibilizar intereses y derechos en muy diferentes circunstancias y supuestos). Hoy, la pérdida por el Estado de Derecho clásico de sus características originarias ha arrastrado consigo su estabilidad en términos que apenas permiten ya utilizar la categoría de Estado de Derecho para la descripción de la pluralidad actual, muy heterogénea, de fenómenos jurídicos determinantes de la emergencia de novedosos problemas precisados de respuesta adecuada. El resultado es que la estructura estatal —al deteriorarse su unidad y articulación jerárquica por efecto de la que se ha denominado "multiplicación heterárquica de las fuentes" o, en otros términos, el "deshilachado" del sistema jurídico estatal mismo- no produce ya la impresión de unidad y homogeneidad, sino más bien la de hibridación de cons-

37 Thomas BURRI ("Do lawyers knead the dough? - How law, chaos, and uncertainty interact", European Journal of Risk Regulation, núm. 4, 2010, pp. 371 a 381), recurriendo a la metáfora (el trabajo de la masa) de los científicos Heinz-Otto Peitgen, Harmut Jürgens y Dietmar Saupe, apunta, por ello, a que el Derecho, para cumplir su cometido de orden, ha de proceder mediante reglas con la lógica de todo sistema dinámico estable de condición iterativa en el modo de su reproducción. 
trucciones que conectan entre sí lo que hasta hace bien poco era incompatible. Lo paradójico es que todas estas evoluciones (en particular la devolución de cometidos administrativos al mercado vía privatización) no han disminuido el espectro de tareas estatales.

Las consecuencias de todas estas transformaciones vienen afrontándose básicamente con estrategias que, en realidad, no van más allá del mantenimiento de una pura apariencia de continuidad, en especial por la vía de la constitucionalización ${ }^{38}$ y para la reafirmación de la potencia vinculante del orden de derechos fundamentales gracias a su ampliación a nuevas dimensiones, califíquense estas como objetiva, prestacional o protectora. Es esta, sin embargo, una bomba de achique (basada en el motor tradicional de la interpretación analógica y teleológica en sede sedicentemente aplicativa) que no está a la altura de los retos que debe afrontar. Pues ante la pérdida de centralidad de la eficacia vinculante de la Ley se imponen: i) la necesidad del recurso a operaciones de ponderación y composición (así en la colisión de derechos constitucionales) corruptoras de la separación funcional de los poderes estatales (como muestran las posibilidades "creativas" de la técnica de la "interpretación conforme" empleada sobre todo en sede jurisdiccional constitucional) ${ }^{39}$; ii) la progresiva juridificación de la política sin que por ello se vean mermadas las posibilidades decisionales del poder; y iii) la privatización, tampoco limitadora, sino, al contrario, ampliadora de la esfera de acción del poder público (como consecuencia del pase a primer plano de la responsabilidad por las consecuencias de la privatización; responsabilidad que está en el origen de la creación de nuevas estructuras jurídico-públicas — concretamente administrativas — en las que tiene lugar ya no tanto la "comprensión" — para

38 Mas allá, incluso, del constitucionalismo estatal. Véase Ricardo ALONSO GARCÍA, El juez nacional en la encrucijada europea de los derechos fundamentales, Thomson-Civitas, Madrid, 2014.

39 El fenómeno aludido en el texto es apreciable igualmente en la evolución más reciente de la función del orden judicial contencioso-administrativo de control del poder público gubernativo-administrativo. Puede ejemplificarse en el alcance de la jurisprudencia del Tribunal Supremo. Salvo en el caso de declaración de nulidad de disposiciones administrativas de carácter general, en que el pronunciamiento casacional del Tribunal Supremo sigue cumpliendo una tarea de control depurador sin más del ordenamiento, la regulación actual del recurso de casación no es que haga realidad el papel de complemento del ordenamiento jurídico que asigna el Código Civil a la doctrina que, de modo reiterado, siente el Alto Tribunal, sino que puede decirse que lleva aquel papel aún más lejos al hacer de la jurisprudencia una regla mediadora necesaria entre el texto de las normas y su aplicación concreta. Pues no puede decirse que siga siendo estrictamente nomofiláctico, al merecer, más bien, la calificación de nomotético. Según resulta de los supuestos en que cabe apreciar la concurrencia del necesario interés casacional objetivo, entre sus finalidades figura el control de la efectividad de la doctrina constitucional y de la jurisprudencia del Tribunal de Justicia de la Unión Europea; finalidades a las que se suma, cuando opera la presunción de concurrencia del aludido interés casacional, la fijación de jurisprudencia y el control de la observancia de la jurisprudencia ya establecida. Por ello y aquí radica la clave, el recurso puede ser admitido a trámite, cuando, invocada una infracción del ordenamiento jurídico (en general: no solo de las Leyes y demás disposiciones) o de la jurisprudencia, el Tribunal estime que presenta interés casacional objetivo para la formación de jurisprudencia". Véase Luciano PAREJO ALFONSO, "Algunas reflexiones sobre la novedad del recurso de casación en el orden jurisdiccional de lo contencioso-administrativo", Revista Andaluza de Administración Pública, núm. 100, 2018, pp. 339-355. 
su aplicación, vía subsunción, en un caso determinado-, cuanto la "concreción" de las normas mediante ulteriores "regulaciones").

No puede sorprender, pues, el surgimiento —en el Derecho público y, en lo que aquí más interesa, el administrativo (más expuesto al cambio)— de una crítica frontal al método jurídico en que se inscribe la lógica del binomio normación-aplicación y, en particular, de la subsunción. La razón no es otra que la imposibilidad del análisis y el tratamiento adecuados de fenómenos actuales, cada vez más frecuentes y de mayor calado, en los que las actuaciones, si bien inscritas orgánicamente en el "ejecutivo", resultan de difícil catalogación. Esto es especialmente visible en:

a) En el campo "ejecutivo" tradicional: las actuaciones administrativas de programación y planificación, así como la de solución socialmente aceptable, en un presente y cara a un futuro inciertos, de complejos entramados de intereses diversos tanto públicos como privados. Y ello en virtud de la suma de: i) el creciente abandono, en la programación de la "ejecución administrativa", del establecimiento de normas o reglas convencionales (que anudan consecuencias jurídicas precisas a supuestos de hecho bien establecidos; tipo de normas cada vez más excepcionales en la programación legal de la acción administrativa) a favor de normas o reglas finalistas (con escasa densidad regulatoria sustantiva); y ii) la operación de la Administración en tales supuestos, más que con discrecionalidad, con holgada libertad de configuración de límites imprecisos reclamante de nuevos modos de proceder (en particular, la ponderación de bienes, derechos e intereses) y productora de decisiones de muy diverso valor jurídico (que alcanza, incluso, el normativo).

Es este un fenómeno que, a su vez y en tanto que reclama la revalorización de los factores de legitimación de tal tipo de actuación (desde el punto de vista del principio democrático), suscita nuevas y numerosas cuestiones, en particular la del reexamen de la función de la organización y el procedimiento administrativos. En particular, y como más adelante podrá verse en detalle, viene provocando una gran dificultad para el encaje de la hoy tan decisiva actuación administrativa en forma de programa o plan (en su caso, de encadenamiento de sucesivos programas o planes articulados entre sí) en los tipos de norma y acto y, como consecuencia, su acomodación al lecho de Procusto de la dicotomía normación-ejecución vía, si no de metonimia, sí desde luego de sinécdoque, con gran perturbación de la funcionalidad debida de la expresada actuación administrativa.

b) Y en el nuevo campo resultante de la retirada del Estado a una posición de garante como consecuencia de la devolución al mercado de la dación de bienes y la prestación de servicios en ciertos sectores: la emergencia de una función "reguladora” novedosa encomendada a autoridades administrativas independientes, que ha de ser capaz de garantizar el cumplimiento por privados del interés general. Pues la privatización acompañada de la regulación de sectores económicos no supone la desaparición de la exigencia de la satisfacción del bien común, aunque sí el logro de esta última mediante una intervención "estatal" indirecta, no finalista y desarrollada con 
muy amplio margen de autonomía dentro de un marco legal de escasa densidad ${ }^{40}$. Aquí se reproduce la dificultad del encaje en el esquema dual normación-ejecución de las novedosas regulaciones, como acredita la calificación por el art. 30.1 de la Ley 3/2013, de 4 de junio, de creación de nuestra más importante Autoridad Administrativa Independiente - la Comisión Nacional de los Mercados y la Competenciade las Circulares (normativas) que esté habilitada a dictar como "disposiciones de desarrollo y ejecución [jsic!] de las Leyes, Reales Decretos y Órdenes ministeriales que se aprueben en relación con los sectores sometidos a su supervisión". En este novedoso ámbito también las disposiciones son, pues, "ejecución".

Por todo ello, se ha podido decir que la cultura administrativa legalista está hoy en retirada ${ }^{41}$. Lo que significa: desplazamiento, aunque no anulación, del interés en la denominada "ejecución", desde la interpretación (es decir: la aplicación) a la actuación dirigida a la solución de problemas sociales. Abandonando el superado dogma de la única solución correcta (en la aplicación), las normas se entienden como programas de actuación que proporcionan el contexto de la formación de la decisión solucionadora del problema social ${ }^{42}$, normalmente complejo, de que se trate (lo que comporta la revalorización de la organización y el procedimiento administrativos). La Ley deja, así, de ser lo que era para pasar a ser programa del que interesa no tanto (aunque también) la precisión de los límites jurídicos que impone según el principio Estado de Derecho, cuanto las posibilidades de configuración social que contiene para garantizar la calidad del cumplimiento de las tareas a que se refiere ${ }^{43}$.

De ahí la afirmación ${ }^{44}$ de que la posición de la Administración en el sistema de poderes públicos no deriva hoy tanto de su contribución funcional (ejecutiva y do-

40 Es resultado esta nueva forma de procura indirecta del bien común de la influencia decidida del Derecho de la Unión Europea que, en su más reciente evolución en este terreno, exige al Derecho interno estatal la diferenciación clara entre Administración incardinada al Gobierno y la Autoridad independiente "reguladora" y el respeto al espacio decisional atribuido a esta última desde la instancia supranacional. Lo que ha dado pie a José María Baño León a hablar de la introducción por esta vía en nuestro Derecho de una específica "reserva de Administración" desconocida por nuestro sistema constitucional. Véase José María BAÑO LEÓN, "Reserva de Administración y Derecho comunitario", en Carlos ESPLUGUES MOTA, Guillermo PALAO MORENO y Manuel Alejandro PENADÉS FONS (coords.), Nuevas fronteras del Derecho de la Unión Europea. Liber amicorum: José Luis Iglesias, Tirant lo Blanch, Valencia, 2012, pp. 837 a 850.

${ }_{41}$ Christoph ENGEL, "Herrschaftsausübung bei offener Wirklichkeitsdefinition", en Christoph ENGEL y Wolfgang SCHÖN (eds.), Das Proprium der Rechtswissenschaft, Mohr Siebeck, Tübingen, 2007, p. 205.

42 Lo que conlleva (algo cuya aceptación resulta aún más difícil, dada la íntima vinculación del control judicial a los principios tradicionales del Estado de Derecho) el abandono también de la perspectiva del control judicial atenida a la "conformidad al Derecho", pues, a diferencia de la lógica propia de la aplicación, en la praxis ha de armonizarse la conformidad a Derecho con la corrección de la decisión o la funcionalidad de la efectuación, en la realidad, de la vigencia del Derecho.

43 Véase Wolfgang HOFFMANN-RIEM, "Eigenständigkeit der Verwaltung", en Wolfgang HOFFMANN-RIEM y Andreas VOSSKUHLE (eds.), Grundlagen des Verwaltungsrechts, vol. I, 2. a ed., C. H. Beck, München, 2012, $\$ 10$, p. 13.

44 Véase Jan Philipp SCHAEFER, Die Umgestaltung des Verwaltungsrechts, Mohr Siebeck, Tübingen, 2016; autor al que se sigue en este concreto punto. 
tada de legitimación propia) a la legitimación democrática del Estado, cuanto más bien de la interacción de normación y aplicación-ejecución, toda vez que la acción administrativa determina la praxis aplicativa de la Ley, proporcionando al legislador en todo caso referencias para evaluar sus normas y aprobar, en su caso, reformas correctoras. Este círculo entre normación y ejecución gira según las órbitas, separadas y prefijadas constitucionalmente, propias de los distintos poderes ${ }^{45}$, pero la imagen del poder público administrativo como un todo se ofrece solo en una visión de encadenamiento dinámico de las instituciones que forman el Estado, confirmando así el acierto de la famosa frase de E. FORSTHOFF (en su Derecho administrativo): es posible describir la Administración, pero no definirla. Lo que no excusa su deslinde funcional respecto de la legislación y el ejercicio del poder judicial. En tanto el legislador traduce las tareas previstas constitucionalmente en un marco ordenador de imperativos de actuación (comprensivo de todas las formas posibles de esta última), haciendo que las Leyes definitorias de tal marco adquieran vigencia, la Administración se ofrece como "ejecución" de las correspondientes tareas públicas en tal marco y conforme a la Ley lato sensu. Pues tal ejecución está dirigida, incluso allí donde no está predeterminada por la Ley ordinaria sustantiva —aunque sí y siempre por la de carácter presupuestario-, por previsiones constitucionales y del Derecho de la Unión Europea (además de las internacionales). Por ello, la superposición de las perspectivas institucional y funcional lleva a la determinación de la Administración como "aseguramiento de la vigencia" o, mejor, "efectuación del Derecho" (en la realidad ${ }^{46}$; conclusión, que comporta la implicación en la "ejecución administrativa” de vigencia de la norma y realidad. De donde se sigue, en definitiva y este es el resultado al que llega J. P. SCHAEFER, que —al no quedar limitada la acción administrativa a la mera ejecución, en línea de continuación, de la norma- es tanto realización del Derecho como creación del Derecho. En definitiva: la Administración transmuta la vigencia normativa en vigencia empírica, lo que permite deslindarla tanto de la "instauración de la vigencia" (generación de la misma, asunto normativo propio del legislador), como del "control de la vigencia" (entendido como comprobación de la vigencia, incluso de su creación, por parte del poder judicial o la jurisdicción constitucional). Pero en el entendido, entonces, que la función ejecutiva comprende todo lo necesario para la efectuación del programa, incluyendo, en su caso, el establecimiento de normas.

45 La separación competencial da lugar a legislación, ejecución y jurisprudencia; la separación organizativa, a la de Parlamento y Gobierno-Administración; y la separación por razón de la legitimación a la democrática directa o indirecta.

46 Esto luce especialmente en el Derecho de la Unión Europea. El art. 197.1 del Tratado de Funcionamiento de la Unión Europea dispone el carácter de asunto de interés común la aplicación efectiva (el empleo aquí del término "aplicación" debe entenderse hecho en amplio sentido) del Derecho de la Unión por los Estados miembros. Y el art. 297.1 del mismo Tratado obliga, por ello, a los Estados miembros a adoptar "todas las medidas de Derecho interno" necesarias para la ejecución de los actos jurídicos vinculantes de la Unión. Téngase en cuenta que la "ejecución” comprende, desde el punto de vista supranacional, todas las medidas normativas y administrativas precisas al efecto. 


\section{LA PLANIFICACIÓN Y EL PLAN COMO CASO TESTIGO}

\subsection{Una singular forma de actuación con un papel cada vez más central}

La planificación urbanística, en tanto que tipo de planificación con mayor decantación, en general, en el ordenamiento positivo, constituye un buen banco de pruebas en el que examinar la cuestión hasta ahora abordada en abstracto. Especialmente idónea al efecto es la regulada en el ordenamiento español, por el desarrollo en él -a partir de la Ley de 12 de mayo de 1956, de régimen del suelo y ordenación urbana- de un complejo, sofisticado y trabado sistema de planificación o planeamiento a doble escala estratégica (ordenación del territorio) y local (ordenación urbanística). Este sistema atraviesa, en efecto, a día de hoy y precisamente por tal circunstancia, un momento en que se hacen visibles algunos - no precisamente secundariosinconvenientes de la condición jurídica atribuida a los planes. Aunque no sea este momento para analizar en detalle las causas (pues interesan más bien sus efectos principales), baste con aludir — dejando de lado la crisis misma de la planificación como técnica capaz de prever y organizar el futuro- a la formalización jurídica — procedimental (como proceso decisional) y sustantiva (como programa de acción y orden a observar) - progresivamente exigente del planeamiento que, en combinación con la pronta consideración del plan en su conjunto como norma (reglamentaria), ha determinado hasta hoy una gestión forzada del sistema urbanístico para su encaje en el esquema clásico dicotómico normación (planificación como elaboración de normas reglamentarias sin más)-ejecución (todo lo relativo a la urbanización y edificación) ${ }^{47}$ y, por tanto, norma (plan)-acto (todo lo que no es decisión planificadora). Se explica así el aludido forzamiento: la no actualización del novum que representa el planeamiento conduce - como exigencia de la operatividad, no obstante, del sistema- a la "reducción" del plan al expresado esquema y, de modo consecuente, al encuadre de la potestad de planeamiento, sin mayor modulación, en la categoría general de la discrecionalidad y su tratamiento como tal tanto en sede de su configuración legal, como en la de su ejercicio administrativo y, por supuesto, en la de control, especialmente judicial.

El plan es, cuando se pone en manos de la Administración Pública, el resultado de un proceder, una actuación, de esta que concluye en una decisión, pero no es - por lo menos aún - una forma de actuación administrativa con entidad propia y enteramente definida. En todo caso, no es reductible al aludido esquema binario en que se agota, de Derecho positivo, el universo de las decisiones de la Administración Pública. Lo ha

\footnotetext{
47 Hasta tal punto es esto así, que la LRJSP y la LPAC, supuestamente fruto de un reflexivo proceso de reforma y actualización del régimen jurídico de las Administraciones y del procedimiento administrativo común, continúan ancladas en el esquema binario clásico (basado en la dicotomía normaciónejecución) y simplemente desconocen los nuevos modelos regulatorios derivados de la evolución del Estado y la sociedad y sus relaciones recíprocas, no haciendo ni mención, desde luego, al instituto del plan (sobre tales nuevos modelos regulatorios y su incidencia en la acción administrativa: Javier BARNES, en su introducción a la obra colectiva Reforma e innovación del procedimiento administrativo por él editada (Ed. Derecho Global, Sevilla 2008, pp. 11 a 69).
} 
venido impidiendo su consistencia (irreductible al aludido binomio) en la agrupación de múltiples y diversas decisiones (armonizadas y articuladas entre sí) de carácter, alcance y pretensión de vigencia diversos (no solo en el plano sustantivo, sino también en el temporal) por razón del criterio determinante: el cumplimiento de ciertos objetivos. Este decisivo criterio determina que lo que importa en el plan no es la naturaleza jurídica de cada uno de los elementos de su contenido (vistos desde categorías generales), sino la funcionalidad de éstos en la contribución a los aludidos objetivos; con la consecuencia de que su agrupación es algo distinto a la suma de los mismos.

La razón de que no se haya decantado aún como forma de actuación administrativa con perfil propio, a pesar de no tratarse de un fenómeno de ahora ${ }^{48} \mathrm{y}$ de imponer la vigente LPAC (art. 3.1, párr. $2^{\circ}$, g) el desarrollo de toda la actuación de todas las Administraciones públicas conforme, entre otros, al principio de planificación ${ }^{49}$, reside en la primacía otorgada en la praxis al empleo sin más de la técnica y su extensión a los más diversos sectores de la acción administrativa ${ }^{50}$ sin otra preocupación que la de las exigencias o los requerimientos de tales sectores según sus características $^{51}$. Se comprende fácilmente que esto sea así, pues si toda decisión que pretenda encauzar, dirigir o regular, sea de forma general y abstracta, sea específica y concreta, un comportamiento o una actuación determinados se ofrece de suyo como "plan",

48 Lorenzo MARTÍN-RETORTILLO BAQUER, "Antecedentes del concepto de plan y referencia a la legislación de fomento del siglo XIX", RAP, núm. 49, 1996, pp. 39 y 40. También: "Presupuestos políticos y fundamentación constitucional de la planificación administrativa", $R A P$, núm. 50, 1966, pp. 111-143; y "Reflexiones sobre la regulación constitucional de la planificación económica", $R A P$, núm. 117, 1988, pp. 23-50.

En Alemania y en la reunión anual de la Asociación de Profesores de Derecho del Estado de 1959 (publicada por W. Gruyter en la serie VVDStRL, núm. 18), Max IMBODEN (uno de los dos ponentes; su ponencia en pp. 113 y ss.) dejó dicho que el plan es una institución conocida ya por el Derecho administrativo clásico (al menos como instrumento urbanístico de fijación de alineaciones) y Klaus OBERMAYER (el otro ponente; su ponencia en pp. 144 y ss.) puso de relieve la dificultad de un concepto de plan dada su carencia de perfiles nítidos a pesar de su utilización generalizada.

49 La formulación legal del principio apela con toda evidencia al sentido más general del término. De acuerdo con el Diccionario de la Real Academia de la Lengua, actualizado a 2017, la voz planificación significa, en la primera acepción, acción y efecto de planificar, verbo este que, a su vez, significa, en segunda acepción, hacer plan o proyecto de acción (la segunda acepción de planificación alude al plan, metódicamente organizado, para obtener un objetivo determinado).

50 Se entiende, pues, la extrema dificultad incluso de la clasificación de los planes y programas. Aunque en algún país, p. ej. concretamente en Alemania, se ha llegado a plantear una regulación legal general en una Ley de principios de la planificación (alusiva a las formas, los tiempos, los instrumentos y los efectos de esta), lo que ha acabado imponiéndose, inevitablemente, con carácter general es la heterogeneidad del fenómeno y, por tanto, de sus manifestaciones, de modo que en la práctica existen tantos planes o programas (y, por tanto, procesos de planificación o programación) como ámbitos o sectores de responsabilidad o actuación de los poderes públicos: planes o programas económicos, financieros, de tráfico o movilidad, transporte, urbanismo, obras y un muy largo etcétera.

51 Basta con aludir a la gestión de los recursos económicos mediante la presupuestación, la sujeción del ejercicio de la potestad reglamentaria a una "planificación normativa" anual (art. 132 LPAC) o, remontándose atrás en el tiempo, a la técnica bien de la representación gráfica del asentamiento poblacional para la ordenación anticipada del correspondiente proceso, bien de la fijación de alineaciones y rasantes para asegurar el orden en la utilización constructiva del suelo. 
la más reciente evolución a partir de la segunda mitad del siglo $\mathrm{XX}^{52}$ ha conducido a la progresiva complejidad e interdependencia de los procesos sociales reales $y$, por tanto, de las decisiones del poder público ${ }^{53}$, con la tendencia del legislador, consecuentemente, a la remisión, en las normas legales, a "planes" administrativos con el fin de lograr una dirección y control óptimos de los correspondientes procesos reales. La revitalización que del recurso a la planificación es observable actualmente no es en modo alguno ajena al Derecho de la Unión Europea ${ }^{54}$. Y ello, aunque tampoco en este ha cuajado un concepto de planificación o programación administrativas como categoría precisa. No es nueva, en efecto, la constatación ${ }^{55}$ de la inexistencia en el Derecho supranacional de un concepto jurídico de planificación o programación como categoría jurídica. No es ya que los Tratados empleen términos tan genéricos como los de orientaciones estratégicas, políticas, medidas o acciones, sino que, cuando utilizan los de plan y programa, lo hacen sin mayor precisión ${ }^{56} \mathrm{e}$ incluso las recientes Directivas que se refieren a planes y programas o prevén su formulación se

52 Véase Joseph KAISER, "Exposé einer pragmatischen Theorie der Planung", en id. (ed.,), Planung I, Nomos, Baden-Baden, 1965. Para este autor el plan es la gran característica de nuestro tiempo resultante de la demanda de tal forma de actuación derivada de la asunción por el Estado de responsabilidades de bienestar social.

53 Todo ello sin perjuicio de que el proceso haya contado con momentos de crisis y escepticismo sobre la utilidad del instrumento, el cual se desarrolla al hilo de la decantación del Estado social y sobre el trasfondo de la superación de la rígida separación decimonónica entre sociedad y Estado. Ya Ernst FORSTHOFF dejó apuntado (Lehrbuch des Verwaltungsrechts, I Band, Allgemeiner Teil, C. H. Beck, München-Berlin, 9. a ed., 1966, pp. 3 y 4; existe traducción española de edición anterior con el título Tratado de Derecho Administrativo, IEP, Madrid, 1958):

"El Estado moderno no encuentra la vida social en un estado de orden preformado. Al contrario: la generación y el mantenimiento de un orden social adecuado ha pasado a ser la primera tarea del Estado, que le exige el empleo de toda su potencia. El medio preferente para ello es la Administración. Con ello la Administración ha dejado de ser un puro mecanismo regulador. Ha pasado a ser, en un sentido comprensivo, una función configuradora. Una tal configuración no puede contentarse con ser en cada caso solamente adecuada, racional y consecuente. Ha de acreditarse también ante las exigencias del Derecho en el sentido de la justicia distributiva y conmutativa.

La realidad social, determinada de modo decisivo por la técnica, la economía y - como consecuencia - la masificación, impone al Estado la obligación de planificar de modo comprensivo y de dirigir; embarazar aquí y fomentar allí; unificar lo fuerte y lo débil en órdenes estables; crear y mantener posibilidades de existencia para millones; distribuir, mantener bajo control y, en su caso, asumir funciones sociales —en corto: actuar, en medio de un mundo de extrema vulnerabilidad, configurando, estabilizando y nivelando [...]".

54 En el seno de la Unión Europea, la expansión e incremento de la importancia de la planificación obedece también, desde hace tiempo, a la influencia de las decisiones supraestatales. En particular, el Derecho ambiental de la UE, por ejemplo, obliga a los Estados miembros a la elaboración de múltiples programas de acción y medidas diversas, sin los cuales y, concretamente, los efectos de coordinación que inducen se torna más que difícil —además — la cooperación interadministrativa entre niveles de la gobernanza comunitaria.

55 Véase al respecto K. Ferdinand GÄRDITZ, Europäisches Planungsrecht, Mohr Siebeck, Tübingen, 2009.

56 No son escasos los preceptos de los Tratados que aluden a instrumentos de planificación o programación. Véanse los arts. 28 y 45 TUE y 42, 47, 68, 139, 168, 180, 182, 185, 186, 187, 189, 192, 197.2, 209, 210 y 309 TFUE. 
abstienen de cualquier definición ${ }^{57}$. Ello no ha impedido, no obstante, la influencia en este terreno del Derecho de la Unión Europea, que se despliega por una doble vía:

a) La repercusión de la planificación de las instituciones europeas, más allá del propio ámbito institucional, en el ordenamiento y la actuación de los Estados miembros ${ }^{58}$.

b) La tendencia creciente al condicionamiento de la autonomía organizativa y procedimental estatal mediante sea la imposición de deberes de planificación a cumplir en régimen de debate público (sobre todo en materia de medio ambiente), sea la inserción de la evaluación estratégica en la planificación estatal.

En cualquier caso puede decirse, como conclusión, que la planificación y, por tanto, el plan se han convertido en una forma central en la actuación de la Administración pública.

\subsection{Una primera aproximación al fenómeno}

La planificación es simultáneamente un proceso (desarrollado y cumplido, jurídicamente, en un procedimiento) y un resultado (jurídicamente: una decisión). En

57 La Directiva 2001/42/CE, del Parlamento Europeo y el Consejo, de 27 de junio de 2001, sobre la evaluación estratégica justamente de planes y programas renuncia a toda definición de plan y programa, conceptos que acotan su ámbito de aplicación, y la Ley que la transpone hoy — Ley 21/2013, de 9 de diciembre, de evaluación ambiental — no añade precisión alguna. El art. 5.2 del texto legal (relativo a las definiciones) se limita a recoger la siguiente: "Planes y programas": el conjunto de estrategias, directrices y propuestas destinadas a satisfacer necesidades sociales, no ejecutables directamente, sino a través de su desarrollo por medio de uno o varios proyectos".

Y la Directiva 2014/89/UE, del Parlamento Europeo y el Consejo, de 23 de julio de 2014, sobre creación de un marco para la ordenación del espacio marítimo, aunque impone a los Estados miembros el establecimiento de una tal ordenación, solo predetermina el resultado de tal establecimiento: el pertinente plan o planes de ordenación, entregando a los Estados miembros la concepción y elaboración (con definición de su formato y contenido) de tal planificación con la sola limitación del respeto de los niveles institucionales y de gobernanza que ellos mismos determinen. Y la transposición interna (Real Decreto 363/2017, de 8 de abril, por el que se establece un marco para la ordenación del espacio marítimo) solo añade la determinación de la figura a emplear: el plan de ordenación para cada una de las demarcaciones marinas, cuya regulación dista de ser mínimamente densa. Es significativo que ambas normas - la europea y la interna - definan la ordenación del espacio marítimo como "el proceso mediante el cual las autoridades competentes analizan y organizan las actividades humanas en las zonas marinas con el fin de alcanzar objetivos ecológicos, económicos y sociales; se entenderá como sinónimo de 'planificación espacial marina' o 'planificación espacial marítima'”.

58 Ejemplos significativos son: i) la evolución de la planificación territorial (para la que la Unión Europea carece incluso de competencia material propia) conducente a la adopción, en la reunión informal de ministros responsables en la materia en Potsdam en 1999, del documento "Estrategia Territorial. Hacia un desarrollo equilibrado y sostenible del territorio de la UE" (cuya influencia en la última evolución de la legislación de ordenación territorial y urbanística tanto estatal como autonómica es notoria); ii) el desarrollo de la política — relacionada con la territorial — regional (fondos estructurales y de cohesión); y iii) la formulación de diversas planificaciones sectoriales (en particular: redes transeuropeas en especial de transporte- y despliegue europeo de espacios de valor ecológico de la Red Natura 2000). 
ambas dimensiones se ofrece como operación basada en la consideración y sopesamiento - a la luz de fines y objetivos — de alternativas (para la elección entre ellas) ${ }^{59}$ y, por tanto, como instrumento en cuya utilización se dispone de un muy amplio margen de libertad para la concreción de fines y objetivos y la determinación de medios o medidas para su realización (lo que quiere decir: en el diseño del modelo u orden a adoptar y, por tanto, la configuración de la realidad social a procurar). Es lógico, pues, que - por su pretensión de encauzar el futuro- constituya un tipo decisional complejo y singular, que no encaja, como ya se ha avanzado, ni en la pura normación (desde luego no en la convencional), ni en la resolución administrativa concreta o con pluralidad de destinatarios (aunque contenga, en mezcla diversa, elementos de una y otra):

- Tiene en común con la legislación (en sentido material), como apunta W. KÖCK ${ }^{60}$, la fijación de premisas de futuras decisiones, pero es distinta de ella por su concentración en la consecución de objetivos y su función de autovinculación a un comportamiento o una actuación futuros de diverso porte. Su diferenciación de la normación, sin embargo, solo es posible atendiendo a que — como ha destacado $\mathrm{H}$. FABER ${ }^{61}$ - consiste en una específica combinación de concreción y multilateralidad por razón de su dependencia del estado de cosas, actual y previsible en el futuro, en la realidad que constituya su objeto.

- No pertenece tampoco a la categoría de los actos, toda vez que se traduce necesariamente en un conjunto de medidas relacionadas indisolublemente entre sí en términos de complementación y dependencia recíprocas; conjunto este que se antepone, antecede, a una pluralidad indeterminada de ulteriores decisiones que justamente pretende dirigir ${ }^{62}$.

Por estas razones ha podido decir E. SCHMIDT-ASSMANN que la planificación supone el diseño de un específico orden (que prepara ulteriores decisiones individuales) en el que destacan la complejidad, la conexidad y la creatividad configuradora ${ }^{63}$.

\subsection{Características distintivas de la planificación y el plan}

La dificultad del encaje de la planificación (el plan) en las categorías establecidas obedece a que desborda el binomio forma de actuación-forma jurídica (entendidos

59 Jörg BERKEMANN ("Horizontale rechtsstaatliche Planung", en Festschrift für Otto Schlichter, Köln, 1995, p. 27, califica el proceso de planificación como "pensamiento en alternativas" centrado en decidir de forma racional sobre opciones para la consecución de fines.

${ }^{60}$ Wolfgang KÖCK, "Pläne", en Wolfgang HOFFMANN-RIEM, Eberhard SCHMIDTASSMANN y Andreas VOSSKUHLE (eds.), Grundlagen des Verwaltungsrechts, vol. II, C. H. Beck, 2. ${ }^{\text {a }}$ ed., München, 2012, pp. 1396 y 1397.

${ }_{61}$ Heiko FABER, Verwaltungsrecht, J. C. B. Mohr (Paul Siebeck), Tübingen, 1989, 2. ${ }^{\text {e ed., pp. }}$ 334 y ss.

${ }_{62}$ En este sentido, Klaus OBERMAYER, "Der Plan als verwaltungsrechtliches Institut", VVDStRL, t. XVIII 1960, p. 144.

${ }_{63}$ Eberhard SCHMIDT-ASSMANN, "Planung unter dem Grundgesetz", DÖV, 1974, p. 542. 
como sinónimos). Pero ello no constituye obstáculo a su consideración, sobre la base de su expuesta singularidad, como verdadero instituto jurídico dotado de notas distintivas y prefigurador de una verdadera forma de actuación, concebida como forma típica, en la praxis, del proceder de la Administración que, por ello, es capaz de cumplir un papel de orden y descarga del quehacer jurídico. Es esencial, pues, la identificación de las características que, de un lado, sean comunes a todas sus manifestaciones y, de otro lado, sean capaces de singularizar la figura respecto a cualesquiera otras formas de actuación. Descartadas por razones obvias las de: i) su carácter prospectivo (todo plan o programa supone, por definición, el establecimiento de un orden que se pretende hacer efectivo en el futuro) ${ }^{64}$; y ii) la autovinculación a un comportamiento o una actuación aún por desarrollar ${ }^{65}$, las que singularizan propiamente la planificación son las que traen causa — como certeramente ha apuntado K. Ferdinand GÄRDITZ ${ }^{66}$ — de su posición y función en el proceso de formulación y gestión de las políticas públicas jurídicamente formalizadas. Posición y función que no son otras que las reconducibles a las de rótula de articulación de la programación normativa abstracta y general de la actuación administrativa, de un lado, y el dictado de los concretos y últimos actos ejecutivos de la misma, de otro. Presenta necesariamente, por ello y desde el punto de vista de las formas jurídicas establecidas, una naturaleza híbrida (aunque solo desde la perspectiva deformante del clásico binomio normación-ejecución) por razón de la combinación de una y otra, de modo que su función consiste en la "concreción" — en medidas de valor y alcance diverso y por relación ya a un determinado complejo o entramado de situaciones reales- del marco normativo habilitante. Por ello, es consecuente al bloque de legalidad (Ley y Reglamentos) en que se inscriba y al mismo tiempo antecedente de la fase individualizada del proceso ejecutivo (en el sentido de que no ultima este último proceso).

La razón del recurso a la calificable, así, de "bisagra planificadora” en el proceso de "efectuación" del programa normativo contenido en el marco legal habilitante radica en que determinadas situaciones o realidades no son accesibles — desde el grado de abstracción que impone su obligada contemplación con una suficiente distancia- a una regulación que, por completa, sea susceptible de ser ejecutada mediante actos

64 Tal carácter en modo alguno es (o debería ser) infrecuente en el quehacer ordinario de la Administración. La acotación de la planificación o programación administrativas requiere su encuadre y diferenciación en el seno de la función ejecutiva y toda normación abstracta y general (desde luego la administrativa convencional, pero también, incluso, la legislativa) supone una programación material más o menos densa de ulteriores decisiones administrativas. Los arts. 3 LRJSP y 132 LPAC disponen, respectivamente, la actuación de las Administraciones públicas conforme, entre otros, al principio de planificación y dirección por objetivos y el deber de dichas Administraciones de hacer público anualmente un plan normativo que contenga las iniciativas legales y/o reglamentarias que vayan a ser elevadas para su aprobación en el año siguiente, debiendo publicar el plan anual normativo en el portal de la transparencia correspondiente.

65 Pues esta nota puede predicarse ciertamente de toda planificación o programación, pero cualifica propiamente a la que despliega sus efectos directos en el ámbito doméstico y no incorpora los que —en sus manifestaciones más depuradas — produce desde luego respecto a terceros y, en particular, la ciudadanía.

66 K. Ferdinand GÄRDITZ, op. cit. en nota núm. 54, pp. 6-9. 
puramente aplicativos (sean concretos o con pluralidad de destinatarios). La complejidad de aquellas situaciones o realidades y la estrecha interdependencia actual de las propias de las relaciones de vida en sociedad demandan, en efecto, la fijación, en el seno de la planificación remitida por el marco legal, de premisas decisionales adecuadas a las reales circunstancias concurrentes (así como su previsible evolución) y, consecuentemente, ajustadas a los problemas a resolver. De donde la disposición multilateral de la planificación y la necesaria prolongación en ella de la normación en términos novedosos; términos estos en los que, además y al propio tiempo que se ultima la regulación (mediante el establecimiento, en el marco del bloque de la legalidad, de una ordenación para éste impracticable), se organiza y articula el proceso ejecutivo hasta su final (proceso este, integrado ya solo por actos, que no pertenece, así, a la planificación misma, es posterior a ella). De lo que se desprende de suyo: i) la importancia - para el acierto y la legitimación de su resultado: el plan- del proceso de planificación ${ }^{67}$, es decir, y en términos jurídicos, el procedimiento de elaboración y aprobación de todo plan ${ }^{68}$; y ii) la inherencia a la planificación (en cuanto proceso dinámico en permanente interacción con su contexto real y social) y, consecuentemente, al plan, de la dimensión temporal (exigente de la elasticidad precisa para resistir y absorber los cambios en el entramado de intereses relevantes para la ordenación por él establecida), de modo que las previsiones de los planes pueden - a pesar de sus pretensiones normativas - caducar (perder de suyo vigencia sin necesidad de derogación o sustitución expresas) ${ }^{69}$.

Por consiguiente, la planificación es, jurídicamente, el proceso de ultimación de la determinación de las relaciones entre posiciones jurídicas diversas a partir y en el marco del pertinente marco legal, que, por circunscrito a una muy limitada prefiguración de las aludidas relaciones, ha descargado en la planificación su precisión a la

${ }^{67}$ Conforme a W. KÖCK, "Pläne”, op. cit. en nota núm. 59, el proceso de planificación (al que debe responder el procedimiento de aprobación del plan correspondiente) debe desplegarse idealmente en las fases de:

- Identificación de los problemas y precisión de fines y objetivos a alcanzar.

- Obtención de datos suficientes sobre el estado de la situación a ordenar y realización de una prognosis sobre su evolución.

Ponderación y valoración de alternativas y toma de la decisión final.

${ }_{68}$ Pues la remisión a una planificación permite: i) descargar la normación abstracta y general, que ha de guardar la necesaria distancia respecto al objeto regulado para cumplir satisfactoriamente su función de preservación de los derechos y libertades; y ii) hacer transparentes y controlables (gracias a su racionalización) los conflictos que existan en la situación o realidad de que se trate mediante el abordaje de la complejidad y la absorción de la incertidumbre de forma escalonada.

${ }^{69}$ Buen ejemplo es, en el planeamiento urbanístico, la clasificación del suelo rural destinado a su transformación mediante la urbanización. Si bien procede considerarla decisión normativa, de ella no cabe predicar (cual, sin embargo, se sigue pretendiendo), una vigencia indefinida (como si de una norma convencional se tratara), pues el cumplimiento del proceso de urbanización de dicho suelo lo convierte de suyo en urbanizado (urbano), perdiendo consecuentemente su anterior condición (a pesar de la permanencia formal de la clasificación en el plan) sin necesidad de derogación o sustitución en cualquier otra forma de tal plan en este punto. Para probarlo, basta con plantear la cuestión de la valoración del suelo una vez urbanizado (persistiendo su clasificación original): ¿sería aplicable la valoración como suelo en situación básica de rural? Evidentemente no. 
luz de las características de la situación o realidad constitutiva de su objeto. Dado que el bloque de la legalidad, por su inevitable escasa densidad, no prefigura soluciones unívocas, el plan no consiste solo en una mera ejecución dirigida por el Derecho, sino sobre todo en una configuración de ámbitos sociales vinculada teleológicamente.

En consecuencia, los planes o programas:

$1^{\circ}$. Son fruto de una programación normativa de escasa densidad y carácter finalista (no condicional), pudiendo ser reconducidos — a pesar de su heterogeneidad y carácter proteico y como hace tiempo puso ya de relieve N. ACHTERBERG ${ }^{70}$ - a la idea del diseńo anticipado de una actuación o conjunto de actuaciones y el fin u objetivo con ella(s) pretendido con el propósito de conseguir lo perseguido del modo más seguro, fácil y rápido. De donde se sigue con toda naturalidad que la planificación es el proceso de elaboración de tal diseño ${ }^{71}$;

$2^{\circ}$. presentan una decisiva dimensión procedimental; y

$3^{\circ}$. si bien cumplen funciones heterogéneas, algunas de ellas están generalizadas o, incluso, son comunes a todos los planes, como sucede con las de i) orientación de la conducta propia (de la Administración) y, en su caso, de los ciudadanos, imponiendo incluso cargas de justificación a los intereses que pretendan hacerse valer en la realidad ${ }^{72}$; e ii) incremento de la racionalidad en la toma de decisiones con programación legal de escasa densidad.

\subsection{El plan como forma específica de actuación}

Queda planteada, así, la cuestión del plan como forma de actuación con identidad propia. Las formas de actuación de la Administración proporcionan un marco jurídico de referencia adecuado tanto a la(s) Administración(es) actuante(s), como al ciudadano destinatario de la actuación administrativa. Sirven eficazmente a la seguridad jurídica, en la medida en que representan una suerte de "Derecho estandarizado" racionalizador de la actuación administrativa (haciendo innecesario el planteamiento y solución, de cada vez, de cuestiones de principio) y facilitador de su eficacia. Constituyen, así, "repositorios" de fórmulas que —salvo dificultades específicas del caso- simplifican la aplicación del Derecho.

70 Norbert ACHTERBERG, Allgemeines Verwaltungsrecht, C. F. Müller, Heidelberg, 1982, pp. 430 y 431.

${ }_{71}$ En sentido prácticamente equivalente el concepto establecido en su momento por Hans-Julius WOLFF, Otto BACHOF y Rolf STOBER, Verwaltungsrecht I, C. H. Beck, München, 10. a ed., 1994, p. 837: la planificación (y, por tanto, su resultado, el plan) no es otra cosa que la preparación sistemática y la determinación de un comportamiento racional para - bajo circunstancias dadas - alcanzar un objetivo del mejor modo posible, que exige la coordinación de intereses diversos y contradictorios a los efectos de la realización de una idea de orden.

72 Véase Eberhard SCHMIDT-ASSMANN, "Struktur und Gestaltungselemente eines Umweltplanungsrechts", $D O ̈ V, 1990$, p. 169. 
Como ya se ha razonado, la planificación y, por tanto, los planes — aun siendo administrativos - se diferencien claramente de la actividad típica de ejecución (en sentido constitucional), pues sus características impiden, en efecto, tanto su encaje en la clasificación tradicional de las formas de actuación administrativa, como su equiparación a ellas. La razón es clara: la aludida clasificación es tributaria de la serie de binomios clásicos inaplicables al fenómeno: actuación ad intra y ad extra; regulación general o abstracta versus regulación individual o concreta; eficacia jurídica o real; unilateralidad-bilateralidad. Se entiende, pues, que todos los intentos doctrinales de reducción al lecho de Procusto del elenco de formas típicas hayan fracasado en lo esencial.

Esta singularidad está lejos, empero, de impedir que la planificación y el plan sean formas irrenunciables de actuación de la Administración moderna a las que es preciso dotar de un preciso perfil. Y ello porque el ordenamiento positivo emplea desde luego, y lo hace profusamente, la figura del plan, haciendo insoslayable la cuestión del modelo de comportamiento aludido con este concepto jurídico y el régimen jurídico que le debe ser propio.

Puede afirmarse así que, por más que especial, se está ante una verdadera categoría, un instituto en sentido estricto. En efecto:

$1^{\circ}$. Constitucionalmente, ni el legislativo ni el ejecutivo están obligados a atenerse a las categorías de norma y acto. Porque la tutela de derechos no fuerza al mantenimiento de la estricta separación que implica tal binomio, ya que la ejecución es sin duda una categoría constitucionalmente abierta a otras formas de actuación. Y en el contexto de los derechos fundamentales no puede dejar de tenerse en cuenta que la planificación es una categoría central de la actuación humana.

$2^{\circ}$. La Ley (la norma) y el derecho subjetivo son hoy insuficientes como piezas constructivas del Estado de Derecho, de modo que — como ha puesto de relieve E. SCHMIDT-ASSMANN ${ }^{73}$ - es preciso desarrollar otros elementos de garantía.

Pues pretendiendo el Estado de Derecho no solo la protección de discretas esferas privadas individuales, sino una racionalización del estado público en el sentido más amplio del término ${ }^{74}$, es imperativo recurrir a planteamientos regulatorios que, desbordando la esfera individual, posibiliten la clarificación de los intereses en el espacio intermedio entre la Ley abstracta y su aplicación concreta $^{75}$. Y ello, en el sentido de

73 Eberhard SCHMIDT-ASSMANN, Das Allgemeine Verwaltungsrecht als Ordnungsidee, Grundlagen und Aufgaben der verwaltungsrechtlichen Systembildung, Springer, Berlin/Heidelberg, 1998, p. 79 (existe una traducción al español realizada por varios autores bajo el título La teoría general del Derecho administrativo como sistema. Objeto y fundamentos de la construcción sistémica, Marcial Pons, MadridBarcelona, 2003).

74 En este sentido, Konrad HESSE, “Grundzüge des Verfassungsrechts der Bundesrepublik Deutschland”, en Konrad HESSE, Siegfried REICKE y Werner HOPPE, "Bauleitplanung und Eigentumsgarantie - Zum Abwägungsgebot des $\$ 1$ Abs. 4 S 2 Bundesbaugesetz", DVBl, 1964, p. 71.

75 Es digno de mención que en su Sentencia de 17 de julio de 1991 el Tribunal Constitucional Federal alemán (BVerfGE 1, 16) ha destacado la condición de la planificación y el plan como institutos jurídicos de un grado medio de concreción. Conforme a esta característica la planificación estatal no 
una racionalización acorde con el ser del Estado de Derecho (interpretado, así, como obligación de racionalidad), a saber: la organización planificada de la realización de las tareas estatales de la manera más funcional y efectiva posible. De donde se sigue con toda naturalidad que la planificación y el plan pueden cumplir funciones importantes de racionalidad en cuanto implican la definición de un orden. En efecto, el plan establece reflexivamente una específica relación entre situación de partida, medios a emplear y fines a alcanzar y articula igualmente —imbricándolos entre sí- los medios (las medidas) pertinentes a tal fin. A los efectos racionalizadores que se siguen de todo ello se suma el que proporciona decisivamente el procedimiento de planificación, entendido como proceso abierto de exposición y clarificación de intereses.

De todo lo cual se infiere, en definitiva, que la planificación y el plan integran una categoría jurídico-administrativa esencialmente abierta, a la que procede aproximarse por tipos concretos. Implican así también una forma de actuación que, sin embargo, se sirve de técnicas jurídicas diversas ${ }^{76}$, pero en la que, por su plasticidad, lucen la imbricación de lo organizativo y lo procedimental y la relación entre función de la tarea administrativa y procedimiento de su desarrollo o cumplimiento. Pero, por ello mismo y cuando menos para el tipo de plan de ordenación territorial y urbanística, un régimen jurídico de invalidez que sea acorde con sus características específicas.

\subsection{La cuestión, irresuelta, de la naturaleza del plan y el régimen jurídico de su invalidez}

El tratamiento por la jurisprudencia contencioso-administrativa consolidada del plan (concretamente el tipo más desarrollado de planificación: el urbanístico) merece, por la reducción sin más de este in totum a una de las formas de actuación típicas (la normación), la calificación de sinécdoque de efectos gravemente distorsionantes por extensiva al todo (el complejo diverso de medidas que supone) del régimen de invalidez de solo uno de sus elementos (el normativo); régimen que conecta a la concurrencia de vicios de invalidez, sean formales, sean sustantivos, un solo efecto: la nulidad. Las consecuencias perturbadoras de esta jurisprudencia en el proceso, a escala nacional, de la planificación, desde luego la urbanística (al complementarse con la doctrina de la nulidad en cascada, desde el instrumento anulado, a lo largo del proceso de planificación sucesivo e, incluso, a los actos concretos de gestión - reparcelaciones, p. ej.— o aplicación —-licencias, p. ej.—, si bien este último aspecto

puede ser asignada de modo inequívoco ni al legislativo ni al ejecutivo. De un lado la planificación no puede ser comprendida como proceso de subsunción de un determinado supuesto real en los elementos del supuesto de una norma general y abstracta. De otro lado, tampoco la decisión planificadora establece criterio o directriz general-abstractos algunos para un número indeterminado de casos. Se trata más bien de un complejo proceso de obtención, selección y elaboración de informaciones, de la fijación de objetivos y de la elección de los medios a emplear. La planificación tiene por ello un carácter finalista y en modo alguno condicional.

76 Hans-Julius WOLFF, Otto BACHOF, Rolf STOBER, Verwaltungsrecht I, C. H. Beck, München,1994, p. 837. 
se ofrece hoy algo moderado), pero también de otros tipos de planes con incidencia territorial y equivalentes determinaciones vinculantes, han dado lugar a un verdadero torrente de literatura crítica $y$, en su caso, propositiva de soluciones ${ }^{77}$ que no ha tenido, por ahora, mayor efecto.

La situación en nuestro inmediato entorno contrasta, así, con la propia, pues en dicho entorno hace ya algún tiempo que se ha tomado conciencia de la distorsión

77 Véanse, en particular:

- José María BAÑO LEÓN, "Reconsideración sobre el régimen de impugnación del plan urbanístico", en El derecho de la ciudad y el territorio. Estudios en homenaje a Manuel Ballbé Prunes, INAP, Madrid, pp. 859-871; "El plan urbanístico en ruina”, Práctica urbanistica, núm. 144, 2017, 8 pp.; y "Un plan jurídico de reforma para los planes urbanísticos", RDUM, núm. 311, 2017, pp. 43-56.

- BASSOLS COMA, "La asimilación de los planes de urbanismo a normas reglamentarias y problemática jurídica de su anulación”, en Gabriel SORIA MARTÍNEZ y Martín BASSOLS COMA (coords.), Los efectos de la nulidad de los instrumentos de planeamiento urbanistico, Thomson ReutersAranzadi, Madrid, 2017, pp. 27-102.

- Eduardo CALVO ROJAS, "Los planes urbanísticos como disposiciones de carácter general. Problemas que suscita la declaración de nulidad de los instrumentos de planeamiento. Suspensión cautelar de la efectividad de los planes impugnados en vía jurisdiccional", en Eduardo GARCÍA DE ENTERRÍA Y MARTÍNEZ-CARANDE y Ricardo ALONSO GARCÍA (coords.), Administración y justicia: un análisis jurisprudencial. Liber amicorum a Tomás Ramón Fernández, vol. I, Civitas, Madrid, 2011, pp. 821-840.

- Miguel CASINO RUBIO, "La impugnación de los planes urbanísticos y la distinción entre el acuerdo de aprobación y el plan aprobado", en Marcos VAQUER CABALLERÍA, Ángel Manuel MORENO MOLINA y Antonio DESCALZO GONZÁLEZ (coords.), Estudios de Derecho Público en homenaje a Luciano Parejo Alfonso, t. III, Tirant lo Blanch, Valencia, 2018, pp. 2973-2998.

- Judit GIFREU I FONT, "Los efectos jurídicos de la anulación del planeamiento urbanístico sobre los actos singulares de aplicación. Especial referencia a los instrumentos de ejecución y títulos administrativos habilitantes dictados a su amparo", en Gabriel SORIA MARTÍNEZ y Martín BASSOLS COMA (coords.), Los efectos de la nulidad de los instrumentos de planeamiento urbanistico, Thomson Reuters-Aranzadi, Madrid, 2017, pp. 145-228; y "La reconsideración de la naturaleza normativa de los instrumentos de planeamiento: ¿ ¿una panacea para modular el alcance y efectos del dogma de la nulidad absoluta de los reglamentos ilegales?", en Jorge AGUDO GONZÁLEZ (coord.), Nulidad de planeamiento y ejecución de sentencias, Bosch, Barcelona, 2018, pp. 21-65.

- Felipe IGLESIAS GONZÁLEZ, "Propuestas de reformas normativas para evitar los actuales efectos de la nulidad del planeamiento urbanístico”, en Jorge AGUDO GONZÁLEZ (coord.), Nulidad de planeamiento y ejecución de sentencias, Bosch, Barcelona, 2018, pp. 231-278.

- Luciano PAREJO ALFONSO, "El plan urbanístico no es solo norma. En pro de la superación de la doctrina simplificadora de su naturaleza", Práctica Urbanistica, núm. 144, 2017, pp. 1-35.

- Juan Alfonso SANTAMARÍA PASTOR, "Muerte y transfiguración de la desviación de poder: sobre las Sentencias anulatorias de planes urbanísticos", RAP, núm. 195, 2014, pp. 197-215; y "Una imprevista disfunción del sistema urbanístico: la mortalidad judicial de los planes", Práctica Urbanística, núm. 141, 2016.

- José Antonio RAMOS MEDRANO, "Más de 90 planes de urbanismo anulados judicialmente por no justificar la disponibilidad de recursos hídricos", Actualidad Jurídica Ambiental, núm. 67, 2017, pp. 4-24.

- Fernando RENAU FAUBELL, "Nulidad radioactiva de los planes urbanísticos por defectos en el procedimiento de aprobación", Noticias Jurídicas, accesible electrónicamente: http://noticias.juridicas. com/conocimiento/articulos-doctrinales/10946-la-nulidad-ldquo\%3Bradioactivardquo\%3B-de-losplanes-urbanisticos-por-defectos-en-el-procedimiento-de-aprobacion/ 
que supone la simple conceptuación del plan como norma y se ha procurado corregir sus efectos distorsionantes sin preocupaciones dogmáticas algunas a la hora de ajustar el régimen de invalidez del plan a sus características propias.

Si, en Francia, el Consejo de Estado había superado ya en sus dictámenes de 12 de diciembre de 1986 y 7 de febrero de 2008 la regla del acarreo ineludible por la nulidad del plan (salvo que el vicio traiga causa directa de este) de la de los actos administrativos que lo han aplicado (en particular las licencias por no constituir solo actos de aplicación del plan), el legislador comenzó en los ańos noventa del siglo XX la adopción de una serie de medidas que han culminado fundamentalmente en el libro VI del código de urbanismo (arts. L-600-1 a 13; versión actualizada de 2019), que - aparte de desconectar, en punto a la aplicación de su respectivo régimen de invalidez, plan de urbanismo e intervención previa de los actos de urbanización/ edificación - ha venido a i) modular y flexibilizar, en el propio código, el régimen de invalidez de los planes (convirtiéndolo, así y por la singularidad del planeamiento, en un régimen específico); y, correlativamente, ii) otorgar al Juez administrativo facultades para, en función del tipo y gravedad de los vicios, apreciar la procedencia de su regularización y, en su caso, la limitación de la anulación a partes determinadas del plan $^{78 / 79}$.

Y en Alemania, las reformas del Baugesetzbuch (código de la construcción) habían conducido ya en 2017 a dotar al capítulo dedicado a "la conservación del planeamiento" (\$\$ 214 y 215) de un contenido centrado igualmente en la precisión para los planes de un régimen específico y propio de invalidez (incluido un plazo específico para hacer valer los vicios de que puedan padecer) ${ }^{80}$. Por ello se ha podido de$\operatorname{cir}^{81}$ que, no obstante la consideración legal de los planes urbanísticos (por el citado código federal de la construcción) como normas municipales, la opinión común hoy sobre la naturaleza jurídica del plan, como categoría, es la de su pertenencia a las decisiones administrativas complejas que se sustraen a una estricta determinación por el legislador parlamentario o, dicho en otros términos, que el instituto sigue sin poder ser encuadrado en una de las formas típicas de manifestación del poder público administrativo y se considera, por tanto, una forma con identidad propia

78 Véase infra el contenido fundamental actual del libro VI del código de urbanismo francés en el Apéndice a este texto.

79 Sobre esta evolución en el Derecho francés, véase Tomás-Ramón FERNÁNDEZ, "Proceso contencioso-administrativo: semejanzas y diferencias de los casos francés y español”, Revista de Urbanismo y Edificación, núm. 29, 2013, pp. 77-95 y "El contencioso urbanístico y su necesaria reforma", $R A P$, núm. 203, 2017, pp.137-162; Juan Ramón FERNÁNDEZ TORRES, "Renovación del Derecho urbanístico en Francia y obligación de apertura de una proceso de debate y reflexión en Espańa”, Revista de Urbanismo y Edificación, núm. 29, 2013, pp. 9-11; y Francisco HERNÁNDEZ GONZÁLEZ, "Novedades en materia de planificación en la nueva legislación del suelo de Canarias: hacia la flexibilidad y simplificación del planeamiento”, Práctica Urbanística, núm. 158, 2019, pp. 1-25.

80 Véase infra el contenido prescriptivo que aquí interesa del capítulo relativo a la conservación del planeamiento del código de la construcción alemán en el Apéndice a este texto.

81 En este sentido, Rainer SCHRÖDER, Verwaltungsrechtsdogmatik im Wandel, Mohr Siebeck, Tübingen 2007, pp. 99-101 y 105-111. 
(un tipo peculiar de actuación del poder público), pero norma únicamente desde la perspectiva de su formalización como tal y en modo alguno de su función o de sus efectos (en particular de su obligatoriedad, toda vez que incapaz para desplegar un efecto de vinculación único y típico).

En España la reacción ha tardado en producirse y se ha visto por ahora frustrada por la situación política que se ha instalado tras la aprobación, el 1 de junio de 2018, de la moción de censura presentada al entonces presidente del Gobierno y aún hoy sigue (a pesar de la celebración de unas elecciones) sin ser despejada en términos permisivos de iniciativas legislativas con posibilidad efectiva de llegar a ser aprobadas. El Gobierno del Partido Popular había elaborado un proyecto de Ley que, desde la perspectiva del refuerzo de la seguridad jurídica en materia urbanística, abordaba la cuestión no tanto desde la directa modulación, en su sede propia, del régimen general o común de invalidez de los actos y las disposiciones administrativos (al parecer por la consideración política en tal tiempo como "intangibles" de la LRJSP y la LPAC), cuanto de la modificación —además de la Ley de suelo — fundamentalmente de la LJCA y para ampliar y flexibilizar las facultades judiciales a la hora de pronunciarse sobre planes urbanísticos y, así, proporcionar cobertura a una decidida "corrección" de la jurisprudencia establecida. Este planteamiento era cuestionable por sectorial ${ }^{82}$ y no pudo prosperar por la moción de censura aprobada los días 31 de mayo y 1 de junio de 2018, por lo que el Gobierno del PSOE surgido de la misma elaboró, ya disueltas las Cortes Generales, un proyecto de Real Decreto-Ley (desde la misma idea del reforzamiento de la seguridad jurídica) que, sin embargo y aun abordando también modificaciones de la legislación urbanística y de la reguladora de la jurisdicción contencioso-administrativa, sí situaba la cuestión en el terreno del régimen común de invalidez de la actuación de la Administración pública, para, modificando los arts. 47, 49 y 51 LPAC y complementando el régimen común de invalidez de las disposiciones administrativas (es decir, sin alterar, ni perturbar, la calificación que se ha establecido ya en nuestro ordenamiento) y respecto a la categoría general de planes con incidencia territorial y carácter vinculante ad extra (con capacidad para imponer obligaciones o legitimar la constitución o el reconocimiento de situaciones jurídicas individualizadas) establecer un régimen de invalidez específico, que parte del común, en los siguientes términos:

a) Limitación de la nulidad de los planes de referencia a los siguientes supuestos:

- Omisión de la evaluación ambiental.

- Omisión del trámite de información pública preceptivo.

- Aprobación en contradicción sustancial con el contenido vinculante de informes sectoriales emitidos en plazo.

82 Al limitarse a "resolver" el problema planteado por la jurisprudencia contencioso-administrativa sobre la invalidez solo del planeamiento urbanístico y prescindir así del carácter más general y sistémico de la cuestión, requirente de una actualización del régimen común de la invalidez del planeamiento, siquiera sea del tipo más evolucionado: el vinculante para los ciudadanos con incidencia territorial. 
- Incursión en arbitrariedad, que haya podido determinar el resultado del procedimiento, en la ponderación de los intereses públicos o privados concernidos.

b) Carácter parcial de la nulidad cuando el vicio afecte solo a determinadas previsiones de las normas que contenga el plan (lo que supone un reconocimiento de la complejidad y, por tanto, heterogeneidad del contenido de este) o a una parte de su ámbito territorial o un área específica.

c) Aplicación, por tanto, a los planes de referencia de la regla de conservación de los actos y trámites cuyo contenido no habría variado de no haberse cometido la infracción de que se trate, con al añadido de la conservación en todo caso de los actos dictados en aplicación de los planes, que hayan quedado firmes o consentidos antes de que la anulación del plan correspondiente tenga efectos generales.

d) Consideración como independientes de los planes e instrumentos de ejecución aprobados en desarrollo de un plan declarado inválido.

Este otro enfoque tampoco ha podido llegar, al menos por ahora, a adquirir vigencia. Pero la paralela presentación en el Congreso de los Diputados por el Partido Popular, en octubre de 2018 y ya sin perspectiva alguna de su tramitación parlamentaria, de una nueva iniciativa legislativa (proposición de Ley igualmente de medidas para reforzar la seguridad jurídica) avala su mayor procedencia, en la medida en que - aunque dicha proposición vuelve a incorporar en gran medida los contenidos del proyecto de Ley caducado - asume en buena medida el régimen específico de invalidez de los planes previsto en el proyecto de Real Decreto-Ley. Aunque lo hace, eso sí, limitando de nuevo el alcance de dicho régimen (al incluirlo en la Ley de suelo y rehabilitación urbana de 2015 y limitar, así, su alcance) y estableciendo una doble naturaleza de los planes urbanísticos: son actos administrativos generales que incorporan, sin embargo, normas.

Se ha abierto paso en nuestro ordenamiento, en todo caso, la idea de la necesidad de actualizar el régimen de invalidez de la actuación administrativa para adecuarlo a las características que la evolución de la función constitucional ejecutiva le ha ido imponiendo, como demuestra el caso paradigmático de la consistente en la planificación.

\section{APÉNDICE}

\subsection{Código de urbanismo francés}

\section{Régimen de invalidez del planeamiento:}

1.1 La ilegalidad de un plan (o un acto acordando la elaboración o la revisión de un plan) por vicio de forma o procedimiento no puede ser invocada por vía de excepción después de transcurridos seis meses desde la entrada en vigor, salvo que el vicio suponga: i) el desconocimiento sustancial o la violación de las reglas de la información pública; o ii) la omisión del informe de presentación o de documentos gráficos. 
1.2 Los instrumentos de planeamiento y las operaciones de: i) elaboración o revisión de un esquema de coherencia territorial o de un plan local de urbanismo; ii) creación de una zona de ordenación concertada; iii) ordenación de la urbanización y edificación que tengan por efecto la modificación sustancial del marco de vida; y iv) proyectos de renovación urbana no son ilegales por el solo hecho de incursión en vicios susceptibles de menoscabar la concertación (que se exige legalmente en los supuestos enumerados entre los habitantes, las asociaciones locales y las restantes personas concernidas), siempre que se hayan respetado las condiciones de tal concertación y los términos establecidos para ella por las Administraciones competentes.

1.3 La anulación o la declaración de ilegalidad de un plan carecen por sí mismas de incidencia en las decisiones relativas a la utilización u ocupación del suelo producidas con anterioridad a dichas anulación o declaración, cuando éstas se funden en un motivo extrańo a las reglas de urbanismo aplicables al proyecto correspondiente.

\section{$2^{\circ}$. Facultades del Juez administrativo:}

2.1. Cuando el Juez administrativo, tras haber constatado que los cualesquiera otros motivos carecen de fundamento, estime que la ilegalidad que afecte a la elaboración o la revisión de un plan es susceptible de ser regularizada, puede, tras conceder a las partes trámite de alegaciones, suspender su resolución hasta la expiración del plazo que fije para tal regularización - plazo durante el cual el plan permanece en vigor - salvo en los supuestos siguientes:

a) Si la ilegalidad apreciada no deriva de un vicio de forma o procedimiento, la suspensión solo puede decretarse si aquella es susceptible de ser regularizada por un procedimiento de modificación del plan conforme al propio código.

b) Si la ilegalidad apreciada lo es por vicio de forma o procedimiento, la suspensión solo puede ser decretada si aquélla ha tenido lugar tras el debate sobre las orientaciones del proyecto de ordenación y desarrollo a largo plazo.

2.2. Notificada al Juez la regularización que se haya producido dentro de plazo, aquél debe —oídas las partes - dictar resolución y, caso de estimar — tras haber descartado otros medios posibles - que el vicio detectado afecta solo a ciertos documentos integrantes del plan, puede limitar a tal parte la anulación que pronuncie.

\subsection{Código de la construcción alemán}

1. Importancia de la violación de disposiciones sobre la elaboración del plan de
utilización de superficies y de las ordenanzas; procedimiento complementario.

1.1. La violación de prescripciones de forma o procedimiento de este código solo tiene trascendencia para la validez jurídica del plan de utilización de superficies y las ordenanzas en los siguientes supuestos: 
a) Cuando, en contra de lo dispuesto en el $\$ 2$, apdo. 3 del código, no hayan sido determinados o valorados correctamente en puntos esenciales los intereses afectados por la planificación, que el Municipio conocía o debía conocer y el vicio sea manifiesto y haya tenido influencia en el resultado del procedimiento.

b) Cuando hayan sido infringidas las diversas disposiciones del código sobre participación del público y de órganos administrativos, salvo que (excepción de carencia de importancia): i) no habiéndose dado — con motivo de la aplicación de las referidas disposiciones - participación a concretos personas, órganos o cualesquiera otros titulares de intereses públicos, los correspondientes intereses eran en todo caso irrelevantes o fueron considerados en la decisión; ii) no se facilitaron indicaciones puntuales sobre los tipos de informaciones de carácter medioambiental que estaban disponibles; iii) concurriendo un motivo importante para una información pública por plazo adecuado superior a un mes, tal plazo mayor no se haya observado y la fundamentación para la apreciación de la no concurrencia de un motivo importante sea comprensible; iv) al aplicar la prescripción relativa a la publicación en internet, se haya ciertamente volcado en internet el contenido del anuncio de información pública y los documentos a interpretar, pero uno y otros no sean accesible a través del portal central del Estado federado; v) al aplicarse, en el procedimiento abreviado regulado en el $\$ 13$, la exigencia de indicación de haberse prescindido de una evaluación ambiental, se haya omitido tal indicación; y v) se hayan desconocido los presupuestos requeridos por las distintas disposiciones del código para el desarrollo de la participación en ellas establecida.

c) Cuando se hayan infringido las diversas prescripciones del código sobre justificación del plan de utilización de superficies o de las ordenanzas, salvo (excepciones de carencia de importancia) que: i) la justificación del plan u ordenanza o su propuesta sea incompleta; y ii) la justificación de la infracción de prescripciones relativas al informe ambiental sea incompleta solo en puntos sin trascendencia.

d) Cuando no se haya adoptado por el municipio acuerdo sobre el plan de utilización de superficies o la ordenanza, no se haya otorgado una autorización o no se haya alcanzado el fin informativo perseguido con la publicación del plan o de la ordenanza.

1.2. También carecen de trascendencia invalidante de los planes directores los siguientes supuestos:

$1^{\circ}$. Cuando no hayan sido valorados correctamente los requerimientos establecidos para la elaboración de un plan de construcción o para la apreciación de motivos apremiantes de elaboración de un plan de construcción anticipado.

$2^{\circ}$. Hayan sido infringidas las previsiones del Código sobre desarrollo de un plan de utilización de superficies mediante un plan de construcción sin que ello haya afectado al ordenado desarrollo urbano previsto en el primero de los planes.

$3^{\circ}$. Se haya desarrollado un plan de construcción sobre la base de un plan de utilización de superficies, cuya invalidez por violación de prescripciones de forma o procedimiento se establezca tras la publicación del plan de construcción. 
$4^{\circ}$. Se haya infringido, en el llamado procedimiento paralelo (tramitación simultánea de un plan de construcción y de un plan de utilización de superficies) la regla legal de que solo se puede anticipar la aprobación del plan de construcción cuando, por razón del estado de los trabajos de elaboración del plan de utilización de superficies, pueda concluirse que aquél va a constituir un desarrollo de las futuras previsiones de este último.

1.3. A los planes de construcción que hayan sido establecidos por el procedimiento acelerado previsto en el código es aplicable, complementariamente a las reglas anteriores (1.1. y 1.2.), lo siguiente:

a) La omisión de las indicaciones relativas a i) la tramitación por el procedimiento acelerado sin evaluación ambiental; ii) el lugar donde el público puede informarse sobre los fines generales, objetivos y efectos principales de la planificación; y iii) el plazo para formular observaciones es irrelevante para la validez del plan.

b) Si la declaración de improcedencia de una evaluación ambiental descansa en un examen previo del caso concreto (conforme a lo dispuesto en el código), este examen previo vale como realizado correctamente de haber sido llevado a cabo conforme a las previsiones del código y ser su resultado comprensible; en cuyo caso es irrelevante que no se haya dado participación a algunos determinados órganos o cualesquiera otros titulares de intereses públicos; de otra manera concurre un vicio de legalidad del plan de construcción.

c) La estimación de no concurrencia del motivo legal para la exclusión del procedimiento acelerado (cobertura del plan de construcción para proyectos que, de acuerdo con la legislación de evaluación ambiental, están sujetos a ésta) vale como correctamente realizada cuando su resultado sea comprensible y el plan de construcción no legitime proyectos incluidos en la sección $1^{\text {a }}$ del anexo 1 de la Ley de evaluación ambiental; en otro caso concurre un vicio relevante para la validez del plan.

1.4. Determina la operación de ponderación la situación fáctica y jurídica al tiempo de la adopción de acuerdo aprobatorio del plan de utilización de superficies o de la ordenanza. Los vicios consistentes en la no acertada determinación o valoración, en puntos esenciales, de los intereses afectados por el plan conocidos o que debían ser conocidos por el municipio y, siendo manifiestos, hayan influido en el resultado del procedimiento no pueden ser hechos valer como vicios de la ponderación; en los restantes casos, los vicios en que incurra el proceso de ponderación son relevantes solo si son manifiestos y han tenido influencia en el resultado de la ponderación.

1.5. El plan de utilización de superficies o la ordenanza puede aprobarse con efecto retroactivo mediante un procedimiento complementario que tenga por objeto la corrección de defectos. 


\section{2a. Plazo para hacer valer la infracción de disposiciones.}

2.1. El transcurso de un año desde la publicación del plan de utilización de superficies o la ordenanza sin que, por escrito y con expresión del motivo de la infracción, se haya hecho valer ésta ante el Municipio torna en irrelevante:

a) Una violación apreciable de algunas de las disposiciones de procedimiento o forma enumeradas en el punto 1.1 .

b) Una violación importante (considerando las reglas expuestas en el punto 1.2) de disposiciones sobre la relación entre el plan de construcción y el plan de utilización de superficies.

c) Un vicio relevante en la ponderación según el punto 1.4.

2.2. En la publicación (que determine la entrada en vigor) del plan de utilización de superficies o de la ordenanza ha de informarse sobre los presupuestos de la impugnación de disposiciones y las consecuencias jurídicas.

\section{BIBLIOGRAFÍA}

Norbert ACHTERBERG, Allgemeines Verwaltungsrecht, C. F. Müller, Heidelberg, 1982.

Ricardo ALONSO GARCÍA, El juez nacional en la encrucijada europea de los derechos fundamentales, Thomson-Civitas, Madrid, 2014.

José María BAÑO LEÓN, "El plan urbanístico en ruina”, Práctica Urbanistica, núm. 114, 2017.

— "Reserva de administración y Derecho comunitario", en Carlos ESPLUGUES, Guillermo PALAO y Manuel Alejandro PENADÉS (coords.), Nuevas fronteras del Derecho de la Unión Europea. Liber Amicorum José Luis Iglesias, Tirant lo Blanch, Valencia, 2012, pp. 837-850.

- "Reconsideración sobre el régimen de impugnación del plan urbanístico", en Judit GIFREU I FONT (dir.), et al., El Derecho de la ciudad y el territorio. Estudios en homenaje a Manuel Ballbé Prunes, INAP, Madrid, 2016, pp. 758-769.

— "Un plan jurídico de reforma para los planes urbanísticos", RDUM, núm. 311, 2017, pp. 43-56.

Javier BARNES, "Introducción”, en Javier BARNES (ed.), Reforma e innovación del procedimiento administrativo, Ed. Derecho Global, Sevilla 2008, pp. 11 a 69.

Martín BASSOLS COMA, "La asimilación de los planes de urbanismo a normas reglamentarias y problemática jurídica de su anulación", en Gabriel SORIA MARTÍNEZ y Martín BASSOLS COMA (coords.), Los efectos de la nulidad de los instrumentos de planeamiento urbanistico, Thomson ReutersAranzadi, Madrid, 2017, pp. 27-102.

Jörg BERKEMANN, "Horizontale rechtsstaatliche Planung”, en Festschrift für Otto Schlichter, Colonia, 1995.

Thomas BURRI, "Do lawyers knead the dough? - how law, chaos, and uncertainty interact", European Journal of Risk Regulation, núm. 4, 2010, pp. 371-381.

Eduardo CALVO ROJAS, "Los planes urbanísticos como disposiciones de carácter general, problemas que suscita la declaración de nulidad de los instrumentos de planeamiento. Suspensión cautelar de la efectividad de los planes impugnados en vía jurisdiccional", en Eduardo GARCÍA DE ENTERRÍA MARTÍNEZ-CARANDE y Ricardo ALONSO GARCÍA (coords.), Administración y justicia: Un análisis jurisprudencial. Liber amicorum a Tomás-Ramón Fernández, Thomson ReutersCivitas, Madrid, 2011, pp. 821-840.

Miguel CASINO RUBIO, "La impugnación de los planes urbanísticos y la distinción entre el acuerdo de aprobación y el plan aprobado", en Marcos VAQUER CABALLERÍA, Ángel Manuel MORE- 
NO MOLINA y Antonio DESCALZO GONZÁLEZ (coords.), Estudios de Derecho Público en homenaje a Luciano Parejo Alfonso, t. III, Tirant lo Blanch, Valencia, 2018, pp. 2973-2998.

Patricia CUENCA GÓMEZ, "Aspectos clave de la teoría del derecho de Adolf J. Merkl”, Revista Telemática de Filosofía del Derecho, núm. 17, 2014, pp. 167-202.

Federico DE CASTRO y BRAVO, Derecho civil de España, Parte general I, Instituto de Estudios Políticos, Madrid, 1955.

Luis DÍEZ-PICAZO y Antonio GULLÓN, Sistema de Derecho civil, 8. a ed., Tecnos, Madrid, 2015.

Christoph ENGEL, "Herrschaftsausübung bei offener Wirklichkeitsdefinition", en Christoph ENGEL y Wolfgang SCHÖN (eds.), Das Proprium der Rechtswissenschaft, Mohr Siebeck, Tübingen, 2007.

Hans-Uwe ERICHSEN, "Das Verwaltungshandeln", en Hans-Uwe ERICHSEN y Wolfgang MARTENS (eds.), Allgemeines Verwaltungsrecht, 9. a ed., Walter de Gruyter, 1992.

Heiko FABER, Verwaltungsrecht, C. B. Mohr, Tübingen, 2. ${ }^{\text {a ed., }} 1989$.

Juan Ramón FERNÁNDEZ TORRES, "Renovación del derecho urbanístico en Francia y obligación de apertura de un proceso de debate y reflexión en España", Revista de Urbanismo y Edificación, núm. 29, 2013, pp. 9-11.

Tomás-Ramón FERNÁNDEZ, "Proceso contencioso-administrativo: Semejanzas y diferencias de los casos francés y español”, Revista de Urbanismo y Edificación, núm. 29, 2013, pp. 77-95.

- "El contencioso urbanístico y su necesaria reforma”, Revista de Administración Pública, núm. 203, 2017, pp. 137-162.

Ernst FORSTHOFF, Lehrbuch des Verwaltungsrechts, I. Band, Allgemeiner Teil, C. H. Beck, München y Berlin, 9. ${ }^{\mathrm{a}}$ ed. 1966.

K. Ferdinand GÄRDITZ, Europäisches Planungsrecht, Mohr Siebeck, Tübingen, 2009.

Judit GIFREU I FONT, "Los efectos jurídicos de la anulación del planeamiento urbanístico sobre los actos singulares de aplicación. Especial referencia a los instrumentos de ejecución y títulos administrativos habilitantes dictados a su amparo", en Gabriel SORIA MARTÍNEZ y Martín BASSOLS COMA (coords.), Los efectos de la nulidad de los instrumentos de planeamiento urbanistico, Thomson Reuters-Aranzadi, Madrid, 2017, pp.145-228.

- "La reconsideración de la naturaleza normativa de los instrumentos de planeamiento: ¿̨una panacea para modular el alcance y efectos del dogma de la nulidad absoluta de los reglamentos ilegales?", en Jorge AGUDO GONZÁLEZ (coord.), Nulidad de planeamiento y ejecución de sentencias, Bosch, Barcelona, 2018, pp. 21-65.

Francisco HERNÁNDEZ GONZÁLEZ, "Novedades en materia de planificación en la nueva legislación del suelo de Canarias: hacia la flexibilidad y simplificación del planeamiento", Práctica Urbanistica, núm. 158, 2019, pp.1-25.

Konrad HESSE, "Grundzüge des Verfassungsrechts der Bundesrepublik Deutschland", en Konrad HESSE, Sigfried REICKE y Werner HOPPE (eds.), Bauleitplanung und Eigentumsgarantie - zum Abwägungsgebot des $\$ 1$ abs. 4 S 2 Bundesbangesetz, DVBl, 1964.

Wolfgang HOFFMANN-RIEM, "Eigenständigkeit der Verwaltung”, en Wolfgang HOFFMANNRIEM, y Andreas VOSSKUHLE (eds.), Grundlagen des Verwaltungsrechts, C. H. Beck, München, 2012.

Juan Felipe IGLESIAS GONZÁLEZ, "Propuestas de reformas normativas para evitar los actuales efectos de la nulidad del planeamiento urbanístico", en Jorge AGUDO GONZÁLEZ (coord.), Nulidad de planeamiento y ejecución de sentencias, Bosch, Barcelona, 2018, pp. 231-278.

Josef ISENSEE, Grenzen. Zur Territorialität des Staates, Duncker \& Humblot, Berlin, 2018.

Joseph KAISER, "Exposé einer pragmatischen Theorie der Planung", en Joseph KAISER (ed.), Planung I, Nomos, Baden-Baden, 1965.

Hans KELSEN, Teoría pura del Derecho, Trotta, Madrid, 2011.

Paul KIRCHHOF, "Rechtsquellen und Grundgesetz", en Christian STARCK et al. (eds.), Bundesverfassungsgericht und Grundgesetz. Festgabe aus Anlass des 25-jährigen Bestehens des Bundesverfassungsgerichts, J. C. B. Mohr, Tübingen, 1976.

Wolfgang KÖCK, "Pläne", en Wolfgang HOFFMANN-RIEM, Eberhard SCHMIDT-ASSMANN y Andreas VOSSKUHLE (eds.), Grundlagen des Verwaltungsrechts, vol. II, C. H. Beck, 2. a ed., München, 2012. 
Karl-Heinz LADEUR, Was bedeutet die "Normativität des Rechts" in der postmodernen Gesellschaft? Vorüberlegungen zur Beobachtung des Rechtssystems durch die Rechts — und die Politikwissenschaft-, accesible en http://www2.jura.uni-hamburg.de/ceri/publ/A2.12.09-neu.pdf.

Oliver LEPSIUS, "Themen einer Rechtswissenschaftstheorie", en Oliver LEPSIUS y Matthias JESTAEDT (eds.), Rechtswissenschaftstheorie, Mohr Siebeck, Tübingen, 2008.

Niklas LUHMANN, Das Recht der Gesellschaft, Suhrkamp, Frankfurt, 1993.

Lorenzo MARTÍN-RETORTILLO BAQUER, "Antecedentes del concepto de plan y referencia a la legislación de fomento del siglo XIX”, Revista de Administración Pública, núm. 49, 1966, pp. 39-48.

- "Presupuestos políticos y fundamentación constitucional de la planificación administrativa", Revista de Administración Pública, núm. 50, 1966, pp. 111-143.

- "Reflexiones sobre la regulación constitucional de la planificación económica", Revista de Administración Pública, núm. 117, 1988, pp. 23-50.

Luciano PAREJO ALFONSO, "Propuestas de reformas normativas para evitar los actuales efectos de la nulidad del planeamiento urbanístico", Práctica Urbanistica, núm. 114, 2017, pp. 1-35.

— "Algunas reflexiones sobre la novedad del recurso de casación en el orden jurisdiccional de lo contencioso-administrativo", Revista Andaluza de Administración Pública, núm. 100, 2018, pp. 339-355.

Gustave PEISER, Droit administratif, Mementos Dalloz, Paris, 10.a ed., 1981.

Antonio Enrique PÉREZ LUÑO, El desbordamiento de las fuentes del Derecho, Wolters Kluwer, Madrid, 2011.

José Antonio RAMOS MEDRANO, "Más de 90 planes de urbanismo anulados judicialmente por no justificar la disponibilidad de recursos hídricos", Actualidad Jurídica Ambiental, núm. 67, 2017, pp. 4-24.

Fernando RENAU FAUBELL, Nulidad radioactiva de los planes urbanisticos por defectos en el procedimiento de aprobación, 2019, http://noticias.juridicas.com/conocimiento/articulos-doctrinales/10946-lanulidad-ldquo $\% 3$ Bradioactivardquo $\% 3 \mathrm{~B}$-de-los-planes-urbanisticos-por-defectos-en-el-procedimiento-de-aprobacion/.

Juan Alfonso SANTAMARÍA PASTOR, "Muerte y transfiguración de la desviación de poder: Sobre las sentencias anulatorias de planes urbanísticos", Revista de Administración Pública, núm. 195, 2014, pp. 197-215.

- "Una imprevista disfunción del sistema urbanístico: La mortalidad judicial de los planes", Práctica Urbanistica, núm. 141, 2016.

- Principios de Derecho administrativo general, 5. a ed., Iustel, Madrid, 2016.

Jan Philipp SCHAEFER, Die Umgestaltung des Verwaltungsrechts, Mohr Siebeck, Tübingen, 2016.

Eberhard SCHMIDT-ASSMANN, "Planung unter dem Grundgesetz", DÖV, 1974.

— "Struktur und Gestaltungselemente eines Umweltplanungsrechts", DÖV, 1990.

- Das allgemeine Verwaltungsrecht als Ordnungsidee. Grundlagen und Aufgaben der verwaltungsrechtlichen Systembildung, Springer, Berlin/Heidelberg, 1998.

Rainer SCHRÖDER, Verwaltungsrechtsdogmatik im Wandel, Mohr Siebeck, Tübingen, 2007.

Christian STARCK, "Rechtsquellen und Grundgesetz", en Christian STARCK et al. (eds.), Bundesverfassungsgericht und Grundgesetz. Festgabe aus Anlass des 25-jährigen Bestehens des Bundesverfassungsgerichts, J. C. B Mohr, Tübingen, 1976.

Hans-Julius WOLFF, Otto BACHOF y Rolf STOBER, Verwaltungsrecht I, C. H. Beck, München, 10. ${ }^{\text {a }}$ ed., 1994. 